\title{
Studies of the Hurricane Evolution Based on Modern Thermodynamics
}

\author{
Chongjian Liu ${ }^{1}$, Ying Liu², Zhexian Luo ${ }^{3}$, Xiaotu Lei", \\ Donghai Wang 5 and Xiaogang Zhou ${ }^{6}$ \\ ${ }^{1}$ Shanghai Typhoon Institute, China Meteorological Administration \\ ${ }^{1}$ State Key Laboratory of Severe Weather, Chinese Academy of Meteorological Sciences \\ ${ }^{2}$ State Key Laboratory of Severe Weather, Chinese Academy of Meteorological Sciences \\ Institute of Remote Sense, Nanjing University of Information Science \& Technology, \\ 4Shanghai Typhoon Institute, China Meteorological Administration \\ ${ }^{5}$ State Key Laboratory of Severe Weather, Chinese Academy of Meteorological Sciences \\ ${ }^{6}$ Training Centre, China Meteorological Administration
}

China

\section{Introduction}

The atmosphere has been likened to a giant thermodynamic engine in which disorganized energy is transformed into the organized kinetic energy of the winds and, the general circulation of the atmosphere can be regarded as simply being driven by temperature differences between the polar and equatorial regions. As a result, some concepts and theories in modern thermodynamics should be relevant and crucial to be used to deeper understanding of the mechanism responsible for the hurricane evolution.

Recently, more attention has been paid to the thermodynamics and statistical mechanics with the atmospheric sciences. In addition to the large number of journal articles (Ozawa and Ohmura, 1997; Duane and Curry, 1997; Barsugli and Battisti, 1998; Egger, 1999; Nicolis, 2002; Fraedrich and Blender, 2003; Gade and Gustafson, 2004), several monographs have been published in succession (Curry, 1999; Bohren and Albrecht, 1999; Tsonis, 2002; Zdunkowski and Bott, 2004).

In this chapter, we will introduce a number of recent studies of hurricane evolution based on modern thermodynamics, which are generally distinguished into the following three categories.

The first category of such studies is closely related with the theory of nonlinear nonequilibrium thermodynamics. As well-known to all, entropy flow is a core concept in the modern theory of dissipative structures just as entropy is in classical thermodynamics and statistical physics. According to the second law of thermodynamics, an isolated system will evolve spontaneously into the equilibrium with maximum entropy where the order or organization of the system is at the minimum. Therefore, negative entropy is very important for a system to keep itself far from its equilibrium, which is also true in biological systems (for a biological individual, equilibrium means death as reflected in the statement in What Is 
Life? by E. Schrödinger that life's existence depends on its continuous gain of 'negentropy' from its surroundings). Based on this cognition, recently the entropy flows of some hurricanes/typhoons have been calculated using the entropy flow formula appropriate for atmospheric dynamical systems with the National Centre for Environmental Prediction/National Centre for Atmospheric Research reanalysis data employed (Liu and Liu, 2004; Liu et al., 2007; Liu and Liu, 2007, 2008, 2009; Xu and Liu, 2008; Liu et al., 2009; Liu et al., 2010). In this chapter, Hurricane Katrina (2005) will be taken as an example to show the main results. This includes that the intensification of net negative (positive) entropy flow entering into Katrina preceded the strengthening (weakening) of its intensity and that the asymmetries of the entropy flow pattern around Katrina's centre in the lower troposphere (e.g. at $850 \mathrm{hPa}$ as shown in Fig. 4 below for entropy flow fields at the two times of 18 UTC 26 and 29 August with the Katrina's track in Fig. 2 for easy reference) contained some significant information on hurricane track prediction. These results imply that classical thermodynamic entropy may serve as an order parameter for an atmospheric system and that entropy flow analysis might provide a new insight into the mechanism responsible for the life cycle of the system.

The second is basically to improve hurricane numerical prediction based on the $2^{\text {nd }}$ law of thermodynamics which implies that if there exists the heterogeneity in a system initially, (say) heat or particles within the system will then be spontaneously transferred (diffused) from part with higher $\mathrm{T}$ or higher concentration to that with lower $\mathrm{T}$ or lower concentration. The evolutionary direction of any many-body system like the atmosphere or ocean must be controlled by the second law of thermodynamics. As a matter of fact, the evolution of a many-body system like the atmosphere in non-equilibrium involves irreversible physical processes such as diffusion within the system. A proper description of diffusion is of critical importance for a numerical weather prediction (NWP) model. However, for example, the commonly used fourth-order diffusion schemes in a NWP model, as employed in the fifth Penn State/NCAR non-hydrostatic meso-scale model (called simply MM5), would show an inadequate diffusion formulation from the point of view of modern thermodynamics. In the recent works (Liu and Liu, 2005; Liu et al., 2009), the forecast accuracy of the MM5 as well as a global spectrum model is improved by emulating physical dissipation as suggested by the second law of thermodynamics that controls the irreversible evolutionary direction of a many-body system. The ability of the new thermodynamics-based scheme to improve model accuracy has been demonstrated via the case of a hurricane as well as a yearlong continuous simulation.

The third category of study is toward improved understanding of hurricane climate change. In this regard, we would like to particularly mention the seemingly counterintuitive phenomena as shown by the analyses based on the observational data, that is, under global warming the tropical cyclone (TC, among which the hurricane is the one of highest intensity) numbers tend to become decreasing over some oceanic basins in the world during the recent multiple decades despite a rise in their sea surface temperatures (SSTs). From our recent work, a methodology of revealing the mechanism responsible for such events has been suggested based on the second law of thermodynamics and the well-known thermal wind relation in the atmospheric dynamics and thus the causality between the unusually heterogeneous pattern of SSTs in warming environment and TC frequency over, as an example, the western North Pacific (WNP) is explained. This methodology is important in that it provides with an insight into the problem why high SSTs under global warming as one of the necessary conditions for TC genesis should unexpectedly contribute to TC number reduction. 
This chapter is arranged as follows: the entropy flows of Hurricane Katrina (2005) are calculated and discussed in the next section; improving hurricane track forecast based on the $2^{\text {nd }}$ law of thermodynamics is presented in the $3^{\text {rd }}$ section; understanding TC frequency variability in terms of thermodynamic principle is given in the $4^{\text {th }}$ section; and further discussions and suggestions are made in the last section.

\section{Implication of entropy flow for the development of a hurricane}

\subsection{A brief introduction}

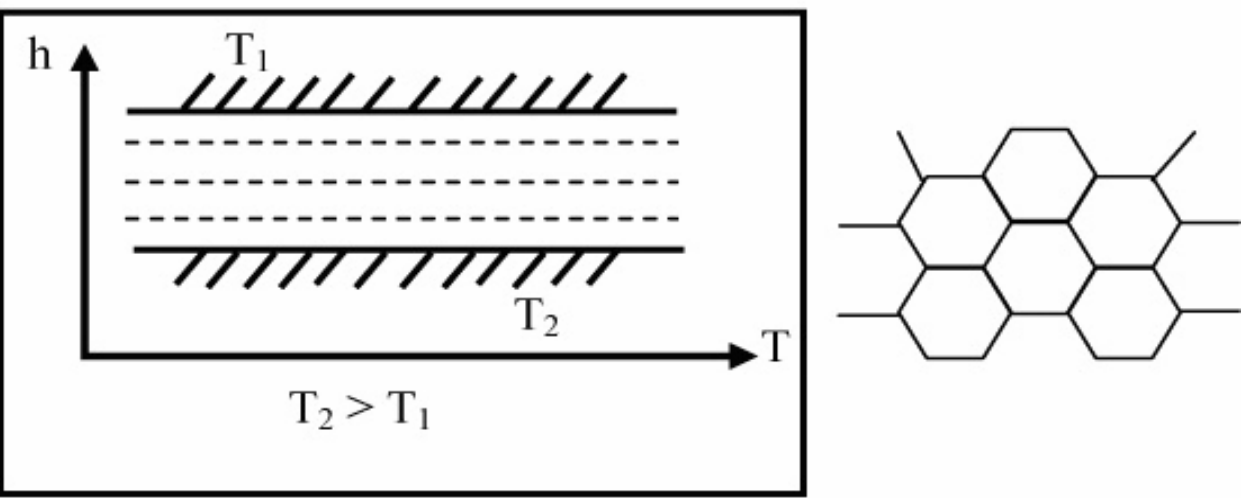

Fig. 1. The schematic diagram for Bénard convection as the prototype of self-organization.

In 1900 Bénard investigated a thin layer of fluid at rest originally, with a free surface at a lower temperature $T_{1}$, heated from its bottom at a higher temperature $T_{2}$ (see Fig. 1), and noticed that a rather regular cellular pattern of hexagonal convective cells was abruptly organised when the temperature difference $\left(T_{2}-T_{1}\right)$ reaching the value of the threshold of primary instability (Prigogine, 1955; De Groot and Mazur, 1984; Glansdorff and Prigogine, 1971; Nitschke, Bestehorn and Thess, 1998), suggesting that every system that obtains heat at a higher temperature but loses heat at a lower temperature will experience net negative entropy flow. In this case the entropy exchange $\left(\delta s_{e}\right)$ of the system with its environment is as follows:

$$
\delta s_{e}=\frac{Q_{2}}{T_{2}}-\frac{Q_{1}}{T_{1}}=\frac{T_{1}-T_{2}}{T_{1} T_{2}} Q<0 ，
$$

where $Q_{1}$ and $Q_{2}$ are the heat fluxes through the top and bottom of the layer, respectively, and $Q$ is the flux when the system becomes steady so that $Q=Q_{1}=Q_{2}$. Later, in 1940s, Schrödinger stated in his monograph "What Is Life?" that life's existence depends on its continuous gain of "negentropy" from its surroundings (Schrödinger, 1944). This implies that negative entropy flow is something very significant for a system, whether it is living or nonliving (Prigogine, 1955; De Groot and Mazur, 1984; Glansdorff and Prigogine, 1971; Schrödinger, 1944; Olby, 1971; Katchalsky and Curran, 1965). That is, negative entropy flow will cause a system initially at equilibrium or even at rest to be organized, or lead a system already at non-equilibrium to a state further from equilibrium (i.e. cause it to strengthen). 


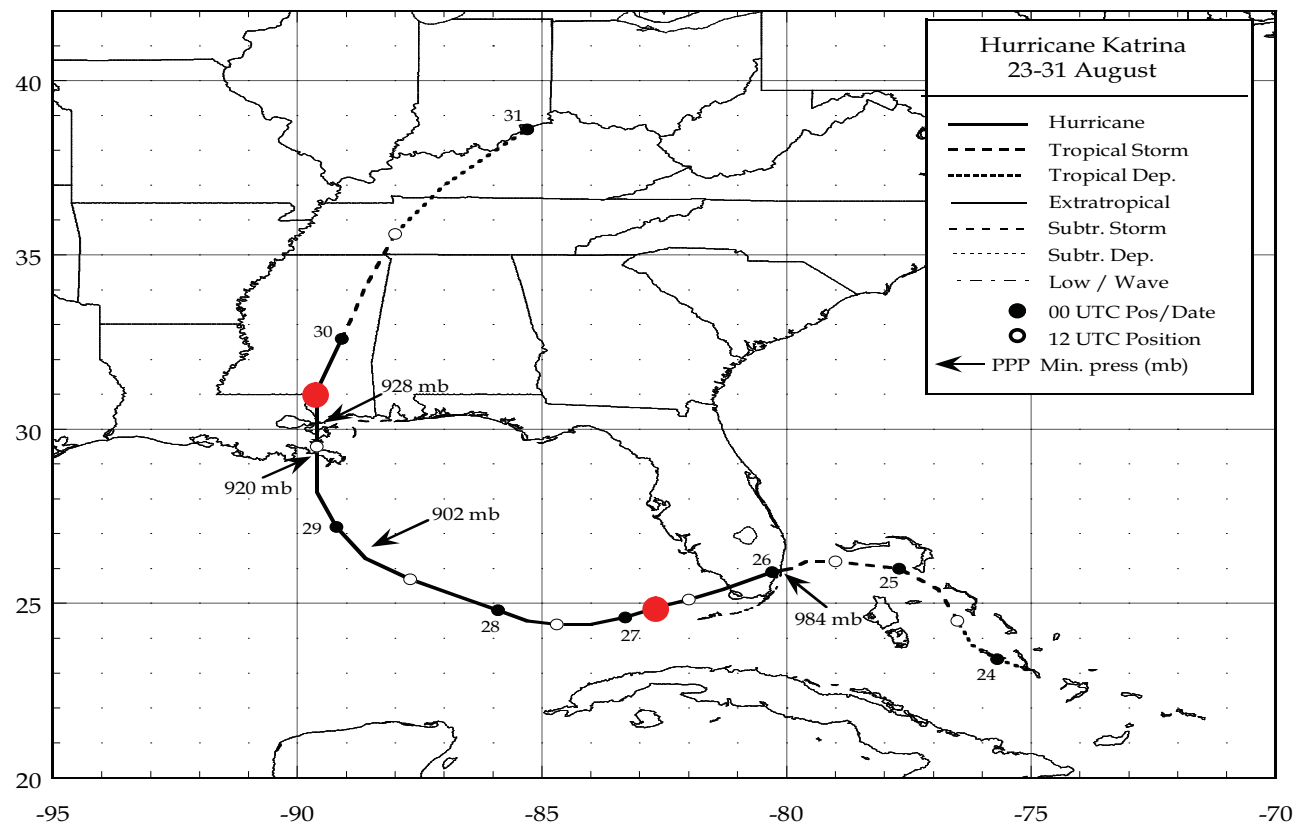

Fig. 2. Best track positions for Hurricane Katrina, 23-30 August 2005. (Credits:

http://www.nhc.noaa.gov/pdf/TCR-AL122005_Katrina.pdf). The red spot marks are for the corresponding position of the hurricane centre's to that shown in Fig. 4.

The purpose of this section is mainly to use the entropy flow formula, as a logical component of the entropy balance equation (Prigogine, 1955; De Groot and Mazur, 1984; Glansdorff and Prigogine, 1971), to calculate the three-dimensional instantaneous entropy flow field and then discuss the relationship of entropy flow with the development of an atmospheric system (hurricane). The system selected for this study is Hurricane Katrina (2005) (see also Fig. 2) that was extraordinarily powerful and deadly with the total damage cost (about $\$ 81$ billion) being roughly double that of Hurricane Andrew (1992) and the total number of fatalities over 1800 (Knabb et al., 2005; McTaggart-Cowan et al., 2007; Liu et al., 1997). Considering the scope of its impacts, Katrina was one of the most devastating natural disasters in the history of the United States.

\subsection{Theory and the computational formulation}

The entropy change in an open system consists of two contributory parts: one is entropy flow that is caused by the positive or negative entropy exchange with its surroundings; and, the other is positive definite entropy production owing to irreversible processes within the system. This can be described by the entropy balance equation which is derived from the Gibbs relation and local equilibrium assumption and, for entropy per unit volume, $S$, is of the form

$$
\frac{\partial S}{\partial t}=-\operatorname{div} \vec{J}_{s}+\sigma
$$

where 


$$
\vec{J}_{s}=S \vec{V}+\frac{1}{T} \vec{J}_{q}-\sum_{k} \frac{\mu_{k}}{T} \vec{J}_{k}
$$

is called the entropy flow vector in which $\vec{J}_{q}, T, \mu_{k}$ and $\vec{J}_{k}$ are the heat flow, temperature, chemical potential and diffusive flow for component $k$, respectively, with the diffusive flow defined as

$$
\vec{J}_{k}=\rho_{k}\left(\vec{V}_{k}-\vec{V}\right)
$$

where $\rho_{k}$ and $\vec{V}_{k}$ are the density and velocity for component $k$, respectively, and $\vec{V}$ the velocity for the mass centre in this context that is related to $\vec{V}_{k}$ by $\vec{V}=\sum \rho_{k} \bar{V}_{k} / \rho$; and, the heat flow expressed approximately, according to the Fourier law (Origogine, 1955; De Groot and Mazur, 1962), as

$$
\vec{J}_{q}=-\rho \tilde{\lambda} \nabla T
$$

where $\tilde{\lambda}$ is the thermal conductivity. In Eq. (2) $\sigma$ denotes the entropy production, the "div"term is the entropy flow, and, the entropy per unit volume $S$ is related to the specific entropy $s$ by $S=\rho$ s with $\rho$ being the density (De Groot and Mazur, 1962; Ruelle, 2003). In this chapter the component of liquid water has been omitted owing to the liquid water content (about $5 \mathrm{~g}$ $m^{-3}$ on the average over the tropics) being much less than the density of either vapour or dry air (Liu et al., 1997; Mason, 1971) and only two components are taken into account, that is, vapour and dry air with the corresponding density being $\rho_{v}$ and $\rho_{d}$, and fractional mass $N_{v}$ (= $q$ the specific humidity) and $N_{d}(=1-q)$, respectively. As a consequence, the entropy $s$ per unit mass consists accordingly of $s_{q}$ for vapour and $s_{d}$ for dry air so that

$$
s=s_{q}+s_{d}=q\left(C_{p v} \ln T-R_{v} \ln e\right)+(1-q)\left[C_{p d} \ln T-R_{d} \ln (p-e)\right],
$$

where $C_{p v}$ and $C_{p d}$ are the specific heat at constant pressure for vapour and dry air, respectively; $e$ the vapour pressure; and, $R_{v}$ and $R_{d}$ are the gas constant for vapour and dry air, respectively. Usually the velocity $\vec{V}_{q}$ for vapour is assumed to be the same as $\vec{V}_{d}$ for dry air so that the diffusive flow $\vec{J}_{k}=0$ in this case since $\vec{J}_{k}=\rho_{k}\left(\vec{V}_{k}-\vec{V}\right)$.

In view of that formulas above are derived based on Cartesian coordinates but the $\mathrm{NCEP} / \mathrm{NCAR}$ reanalysis data used in this letter are on constant pressure layers (Kalnay et al., 1996), it is necessary to transform the expression of entropy flow into that in the $p$ coordinates based on the common transform relations (Haltiner and Martin, 1957).

$$
\begin{aligned}
& \frac{\partial A}{\partial x}=\left(\frac{\partial A}{\partial x}\right)_{p}-\frac{\partial A}{\partial p} \frac{\partial p}{\partial z}\left(\frac{\partial z}{\partial x}\right)_{p}, \\
& \frac{\partial A}{\partial y}=\left(\frac{\partial A}{\partial y}\right)_{p}-\frac{\partial A}{\partial p} \frac{\partial p}{\partial z}\left(\frac{\partial z}{\partial y}\right)_{p}, \\
& \frac{\partial A}{\partial t}=\left(\frac{\partial A}{\partial t}\right)_{p}-\frac{\partial A}{\partial p} \frac{\partial p}{\partial z}\left(\frac{\partial z}{\partial t}\right)_{p},
\end{aligned}
$$


where $\mathrm{A}$ is an arbitrary variable; all derivations made in $p$-coordinates are denoted by ()$_{p}$ and the others otherwise in $z$-coordinates. As a result, the entropy flow becomes finally

$$
\begin{aligned}
- \text { div } \vec{J}_{s} & =-\frac{\partial \rho s u}{\partial x}-\frac{\partial v s v}{\partial y}-\rho \frac{\partial \rho s u}{\partial p}\left(\frac{\partial \phi}{\partial x}\right)-\rho \frac{\partial \rho s v}{\partial p}\left(\frac{\partial \phi}{\partial y}\right)-\rho \frac{\partial s \omega}{\partial p} \\
+ & \frac{\tilde{\lambda} \rho}{T}\left\{\frac{\partial^{2} T}{\partial x^{2}}+\frac{\partial^{2} T}{\partial y^{2}}+2 \rho \frac{\partial \phi}{\partial x} \frac{\partial^{2} T}{\partial p \partial x}+2 \rho \frac{\partial \phi}{\partial y} \frac{\partial^{2} T}{\partial p \partial y}+\rho^{2}\left[\left(\frac{\partial \phi}{\partial x}\right)^{2}+\left(\frac{\partial \phi}{\partial y}\right)^{2}\right] \frac{\partial^{2} T}{\partial p^{2}}\right. \\
+ & \rho\left(\frac{\partial^{2} \phi}{\partial x^{2}}+\frac{\partial^{2} \phi}{\partial y^{2}}+\rho \frac{\partial \phi}{\partial x} \frac{\partial^{2} \phi}{\partial p \partial x}+\rho \frac{\partial \phi}{\partial y} \frac{\partial^{2} \phi}{\partial p \partial y}\right) \frac{\partial T}{\partial p}+\rho^{2} g^{2} \frac{\partial^{2} T}{\partial p^{2}} \\
+ & \left(\frac{1}{\rho} \frac{\partial T}{\partial x}+\frac{\partial \phi}{\partial x} \frac{\partial T}{\partial p}\right)\left(\frac{\partial \rho}{\partial x}+\rho \frac{\partial \rho}{\partial p} \frac{\partial \phi}{\partial x}-\frac{\rho}{T} \frac{\partial T}{\partial x}-\frac{\rho^{2}}{T} \frac{\partial T}{\partial p} \frac{\partial \phi}{\partial x}\right) \\
+ & \left.\left(\frac{1}{\rho} \frac{\partial T}{\partial y}+\frac{\partial \phi}{\partial y} \frac{\partial T}{\partial p}\right)\left(\frac{\partial \rho}{\partial y}+\rho \frac{\partial \rho}{\partial p} \frac{\partial \phi}{\partial y}-\frac{\rho}{T} \frac{\partial T}{\partial y}-\frac{\rho^{2}}{T} \frac{\partial T}{\partial p} \frac{\partial \phi}{\partial y}\right)+\frac{\rho^{2} g^{2}}{T}\left(\frac{\partial T}{\partial p}\right)^{2}\right\}
\end{aligned}
$$

where $u$ and $v$ are the velocities in the $x$ - and $y$-direction at constant pressure layers, respectively; $\omega$ the vertical velocity in $p$-coordinates; $\phi$ the geopotential height with $\phi=g z$ in which $g$ is the gravitational acceleration; and $s$ the specific entropy, expressed mathematically in terms of Eq. (5) in this chapter.

Next we will examine the three-dimensional entropy flow fields, with the computational domain covering the hurricane and its ambient zones, in two ways. One of them is to discuss the vertical cross sections of entropy flow (see fig. 4) based directly on the computational from Eq. (9) and, the other is for the total entropy flow (see Fig. 5) of the hurricane through its lateral boundary, $\sum$, which is calculated by integrating the divergence of the entropy flow vector $\vec{J}_{s}$ over the whole system volume $\mathrm{V}$, and a discrete version of this integration is done here by summing over all the gridpoints encompassed by the curved surface. The latter is based on the well-known Gaussian formula (Bronshtein and Semendyayev, 1997):

$$
\iint_{\Sigma}(P \cos \alpha+Q \cos \beta+R \cos \gamma) d \sum=\iiint_{V}\left(\frac{\partial P}{\partial x}+\frac{\partial Q}{\partial y}+\frac{\partial R}{\partial z}\right) d x d y d z
$$

where $\cos a, \cos \beta$ and $\cos \gamma$ are the direction cosines of the curved surface $\sum$ at the positive normal direction, and $P, Q$ and $R$ are the three components of the entropy flow vector $\vec{J}_{s}=P \vec{i}+Q \vec{j}+R \vec{k}$ in the $x-, y$ - and $z$-directions, respectively.

The total entropy flow calculation for a hurricane is performed by summing the entropy flow over every gridpoint within this system at a constant pressure layer and then over every layer. Therefore, a single figure may stand for the intensity of entropy flow for the system at any given time. The approximate total entropy flow is calculated first on each pressure layer, by summing over all gridpoints within a circle centred on Katrina's centre with its radius of six degrees (thus the horizontal boundaries of the hurricane are defined), and then summed over all layers (thus the top and bottom pressure layer are treated as the vertical boundaries of Katrina). 


\subsection{Results and discussion}

We will first examine changes in the total entropy flow of Hurricane Katrina based on the National Centers for Environmental Prediction/National Center for Atmospheric Research (NCEP/NCAR) $1^{\circ} \times 1^{\circ}$ (latitude-longitude) resolution reanalysis data (Kalnay et al., 1996).

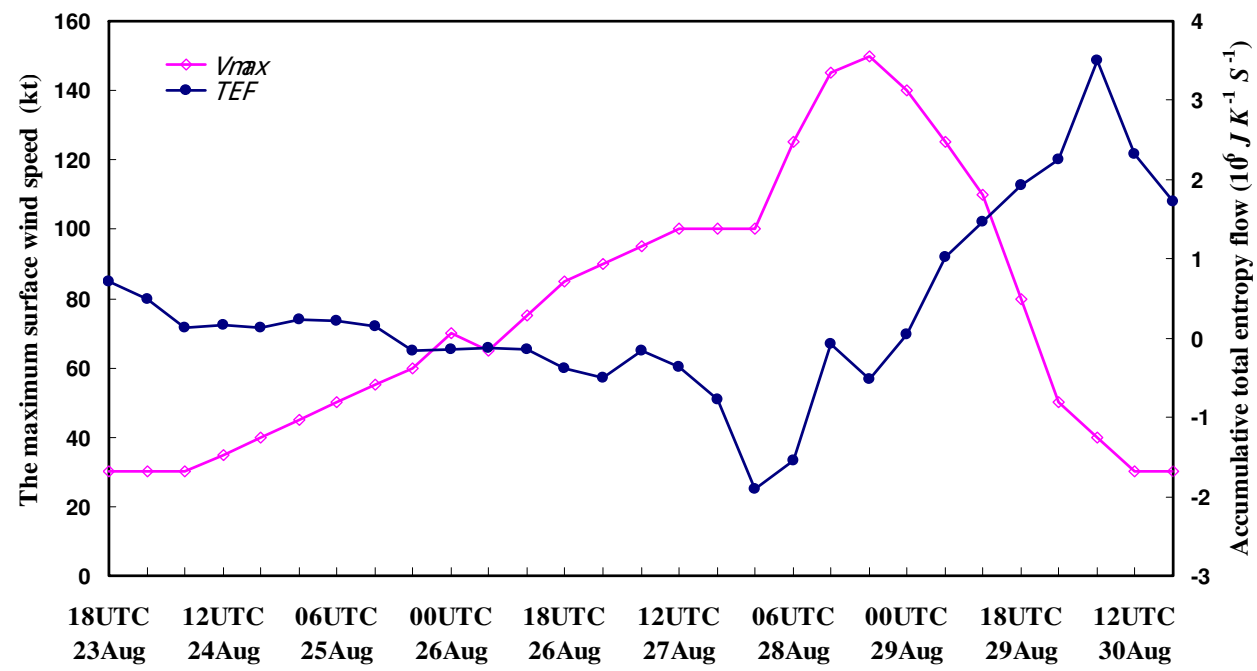

Fig. 3. The evolution of total entropy flow (TEF, in $\left.10^{6} \mathrm{~J} \mathrm{~K}^{-1} \mathrm{~s}^{-1}\right)$ for Hurricane Katrina at 6hourly intervals, with changes in the maximum sustained wind speed $\left(V_{\max }\right.$, in $\left.k t\right)$ as a reference.

Figure 3 shows changes, at 6-hourly intervals, in the accumulative total entropy flow for Katrina as well as the corresponding maximum sustained wind speed representative of the intensity of the hurricane. It is seen from Fig. 3 that there exists a general trend of countercorrelation between these two curves with the phase in the total entropy flow preceding that in the maximum wind speed. For example, Katrina experienced more and more increasing net negative entropy flow before 00:00 UTC 28 August 2005 and, which was followed closely by its continuous intensification with very rapid strengthening occurring on the morning of 28 August. On the other hand, the values of negative entropy flow for Katrina decreased distinctly and even turned to positive entropy flow after 00:00 UTC 28 August, which was followed by the gradual weakening of Katrina from its peak intensity of $150 \mathrm{kt}$ later at 18:00 UTC 28 August. Especially, Katrina had experienced a dramatic decrease of negative entropy flow and a successive turn to the stage of positive entropy flow during the period from 18:00 UTC 28 to 06:00 UTC 29 August when the very rapid weakening of Katrina followed accordingly 6 hours later starting with 12:00 UTC 29 August. As a result, the total entropy flow of a hurricane may contain some significant information conducive to its intensity forecast.

In addition, it is found that the asymmetries of the entropy flow pattern around Katrina's centre in the lower troposphere (e.g. at $850 \mathrm{hPa}$ as are shown in Fig. 4 for the two times of 18 UTC 26 and 28 August which are marked also with the red spot on the Katrina's track in Fig. 2 for easy reference) contained some significant information on hurricane track prediction. 


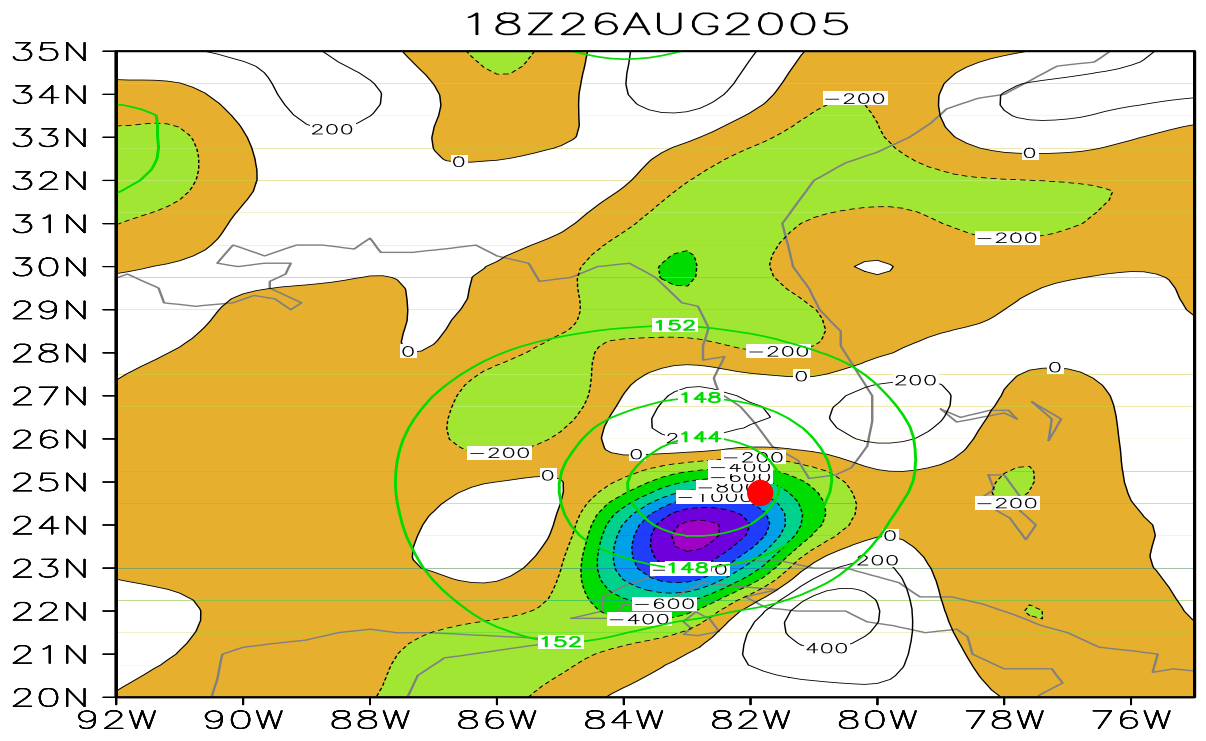

$18 Z 29 A \cup G 2005$

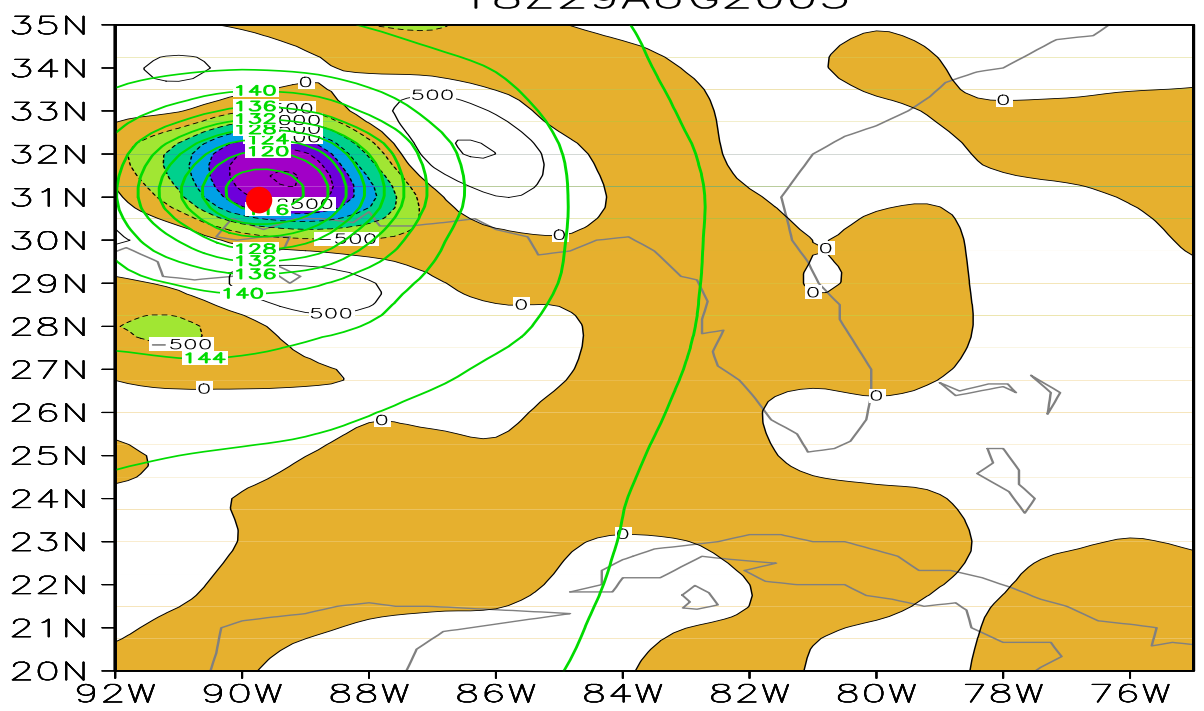

Fig. 4. The entropy flow fields at 850 hPa at 18:00 UTC 26 and at 18:00 UTC 29 August 2005 (the time is marked above the respective panel). The red spot stands for the corresponding position of the hurricane centre's to the respective time.

These results imply that classical thermodynamic entropy may serve as an order parameter for an atmospheric system and that entropy flow analysis might provide a new insight into the mechanism responsible for the life cycle of the system. In view of that Katrina (2005) tends to move towards the side of its centre with stronger negative entropy flows, the entropy flow patterns in the lower levels (e.g. $850 \mathrm{hPa}$ ) might act as an indicator of the 
hurricane track. This is understandable from the theory of dissipative structures (Nitschke et al., 1998): negative entropy flow entering into an open system will potentially enable the system to depart further from equilibrium or cause it to strengthen, and so here a region of stronger negative entropy flow might become a likely area that the hurricane will approach.

\section{Improving hurricane track forecast based on the $2^{\text {nd }}$ law of thermodynamics}

\subsection{A brief introduction}

The evolution of a many-body system like the atmosphere in non-equilibrium involves the irreversible physical processes such as diffusion within the system. A proper description of diffusion is of critical importance for a numerical weather prediction (NWP) model (Smagorincky, 1963; Eliasen and Laursen, 1990; Stephenson, 1994; Becher, 2001; Burkhardt and Becher, 2006).

In the early NWP models (Cheng, 1975) the second order diffusion schemes were, indeed, introduced as a dissipative term similar to viscosity into a prognostic equation, which is basically the physically meaningful Fickian diffusion process. However, it is questionable whether the second order scheme can adequately describe mixing processes in the atmosphere. During the 1980s some models progressed to the fourth or higher order diffusion schemes (Anthes et al., 1987; Laursen and Eliasen, 1989). The fourth-order schemes became the most common choice since they have stronger scale-selectivity compared with the second-order schemes (Pielke, 1984). Now the problem arises since a fourth order scheme may create upgradient mass or heat transport, which is spurious and violates the full irreversibility principle of the second law of thermodynamics. In nature, models that use the fourth order diffusion scheme may produce non-physical oscillations like Gibbs phenomenon (Pielke, 1984). Although the new formulation of horizontal momentum diffusion suggested by Becker (2001) is very creative with a firm physical basis, which defines well the local frictional heating rate (dissipation). However, the point might lie in that the dissipation is positive definite only in the case of nabla-square symmetric horizontal diffusion. Therefore, as pointed out in Becker (2001), the physical meaning of higher orders is open to question even if the stress tensor is symmetric. Recently, Burkhardt and Becker (2006) argue even that the new horizontal scheme developed and tested requires the replacement of the hyperdiffusion with a $\nabla^{2}$-scheme (in order for horizontal dissipation to be positive definite or keep the full irreversibility). To sum up, $\nabla^{2}$-scheme has been replaced by $\nabla^{4}$-scheme owing to the latter's merit of better scale-selectivity. Now, we find that $\nabla^{4}$ scheme can not guarantee being positive definite and then have this chapter of ours to present for suggesting a new scheme that can both remove two-gridlength waves and keep the full irreversibility with the basic theory introduced in section 3.2 below.

The full irreversibility principle exerts an entropy constraint on irreversible processes in a many-body system. The studies (Liu and Liu, 2004, 2005) demonstrated, the discretized atmospheric system must still satisfy the second law of thermodynamics, and improved simulations can be achieved when the irreversibility principle is enforced in a NWP model. The discretization stencil for the diffusion algorithm in a NWP model presented in this chapter is just based on full irreversibility and, the physics-based "fourth-order" scheme would lead to dramatic improvements in the model outputs as viewed when the new scheme based on the theory described in next section is applied to a meso-scale model (Dudhia, 1993; Grell et al., 1995). 


\subsection{Theory}

The principle of the new diffusion algorithm can be briefly described as follows.

Generally the horizontal diffusion of a prognostic variable, $A$, is modeled by adding an ad hoc term, $F_{H A}$, to the right-hand side of the prognostic equation for $A$ :

$$
\frac{\partial A}{\partial t}=N+F_{H A}
$$

where $F_{H A}$ is just the diffusion-like term added and $\mathrm{N}$ denotes all terms other than diffusion. The commonly used fourth-order diffusion schemes, as employed in the fifth Penn State/NCAR non-hydrostatic meso-scale model (MM5) (Grell et al., 1995), would show an inadequate diffusion formulation from the point of view of the classical thermodynamics. For simplicity let us consider the central finite difference form of the one-dimensional fourth-order diffusion terms in MM5:

$$
\begin{aligned}
\left(F_{H A}\right)_{i} & =-K_{A} \nabla^{4} A_{i} \\
& =K_{A}\left[4\left(A_{i+1}+A_{i-1}\right)-\left(A_{i+2}+A_{i-2}\right)-6 A_{i}\right] \\
& =K_{A}\left[4\left(A_{i+1}-A_{i}\right)+4\left(A_{i-1}-A_{i}\right)-\left(A_{i+2}-A_{i}\right)-\left(A_{i-2}-A_{i}\right)\right],
\end{aligned}
$$

where $K_{A}$ is a positive definite diffusion coefficient and, $A_{i}, A_{i \pm 1}$ and $A_{i \pm 2}$ are the values of $A$ at grid points $i, i \pm 1$ and $i \pm 2$, respectively.

From Eq. (12), it is apparent that the gradients between $A_{i}$ and $A_{i+1}\left(A_{i-1}\right)$ ensure mass or heat downgradient transport, but the gradients between $A_{i}$ and $A_{i+2}\left(A_{i-2}\right)$ cause mass or heat to transport upgradiently, which is not in agreement with the full irreversibility principle. Therefore, the fourth-order diffusion scheme expressed in Eq. (12) is not guaranteed to be a monotonic scheme (Crandall and Majda, 1980).

The horizontal diffusion scheme in MM5 can be reconstructed in accordance with the principle of full irreversibility by changing the sign of the $A_{i \pm 2}$ terms in Eq. (12) to enforce an irreversible diffusion process. This new form is:

$$
\left(F_{H A}\right)_{i}=K_{A}{ }^{\prime} \nabla_{T} A_{i}
$$

where $K_{A}{ }^{\prime}$ is a positive definite diffusion coefficient which might have a different value from $K_{A}$ but is kept unchanged in the present new scheme, and $\nabla_{T} A_{i}$ is given by:

$$
\nabla_{T} A_{i}=D_{1}\left[\left(A_{i+1}-A_{i}\right)+\left(A_{i-1}-A_{i}\right)\right]+D_{2}\left[\left(A_{i+2}-A_{i}\right)+\left(A_{i-2}-A_{i}\right)\right],
$$

where $D_{1}$ and $D_{2}$ are the diffusive weights. Now all the signs are positive except for those preceding the $A_{i}$ terms.

It is seen from Eq. (14) that this new scheme is in line with full irreversibility since this scheme ensures the diffusion term must always transport mass or heat downgradiently.

Next we would first verify the merit of this theory with the one-dimensional viscous Burgers equation that has an exact solution when it runs to a steady flow.

The one-dimensional viscous Burgers equation can be written as

$$
\frac{\partial u}{\partial t}+u \frac{\partial u}{\partial x}=\frac{1}{R_{e}} \frac{\partial^{2} u}{\partial x^{2}}
$$


where $u \equiv u(x, t)$ is the flow velocity, $R_{e}$ the Renolds number with $R_{e}=100.0$ set in this chapter. Such a dissipative flow without forcing will eventually tend to the steady flow. If, for example, the initial condition is taken as the linear distribution

$$
u=-x \text { at } t=0,-\infty<x<\infty
$$

with the boundary condition as

$$
u=\left\{\begin{array}{rll}
1 & \text { at } & x=-\infty \\
-1 & \text { at } & x=\infty
\end{array}\right.
$$

there then exists a special solution : $u=-\operatorname{th}\left[\left(\mathrm{R}_{\mathrm{e}} / 2\right) x\right]$, that is a steady solution containing no time. In case the central difference scheme is used it will approach, starting from the initial condition Eq. (16) and integrating till a certain time (within $2 s$ ), this special solution with a certain accuracy.

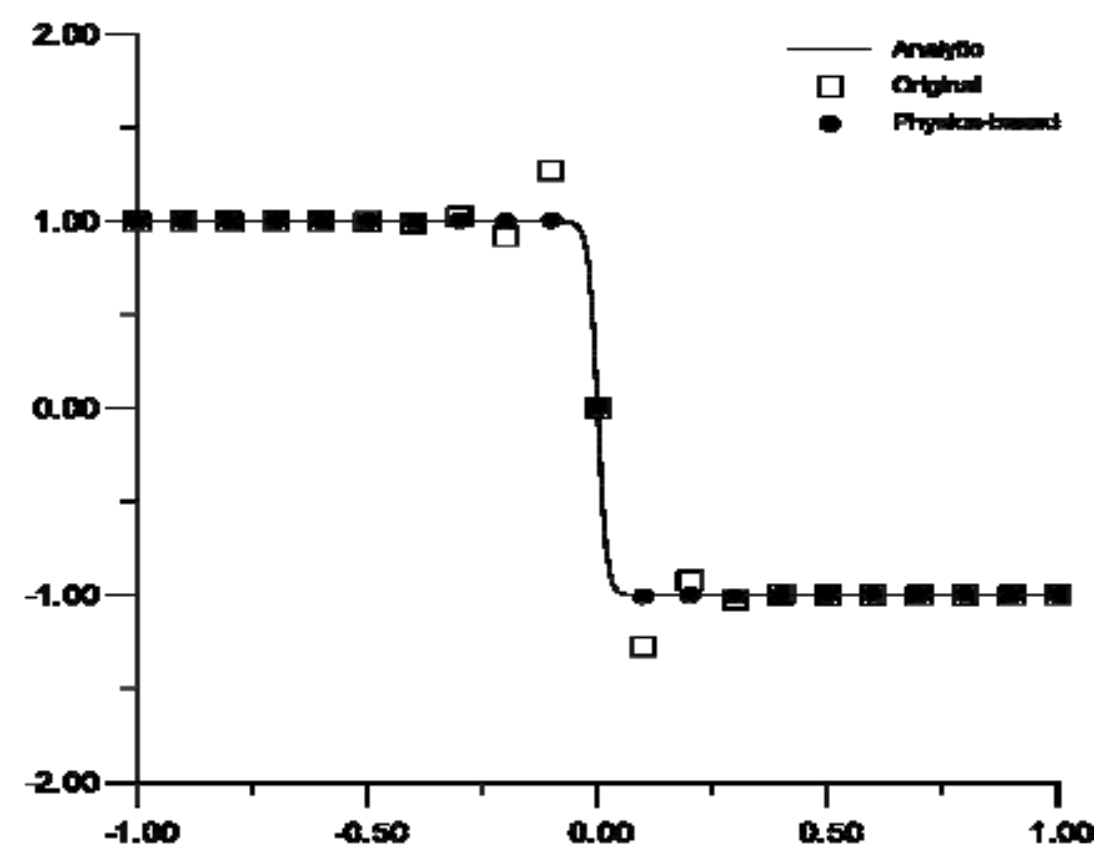

Fig. 5. Comparison of the analytic solution of the one-dimensional viscous Burgers equation that runs to a steady flow with the numerical solutions between the original and physicsbased diffusion schemes used (see text for the details).

The computational results show that the final solution with the original diffusion scheme used has a Gibbs oscillation (Pielke, 1984) near the "shock wave" where the velocity gradient augments suddenly (Fig. 5). On the other hand, the numerical solution consistent with the analytic one is reached when the (original fourth order) scheme is changed, based on the theory described in this section, to the physics-based scheme that meets the restriction of the second law of thermodynamics (Fig. 5). 
In the next section the effect of the physics-based diffusion scheme will be demonstrated via a series of numerical simulations, especially that of a hurricane in terms of its surface minimum pressure and maximum wind.

\subsection{Results and discussion}

In this section the diffusion scheme is re-constructed based on the second law of thermodynamics to ensure downgradient transport in the way described above and then applied to the Penn State/NCAR non-hydrostatic mesoscale model (Grell et al., 1995) with Hurricane Andrew (1992) taken as a case to simulate with the emphasis on the evolutions of its surface maximum velocity $\mathrm{U}_{\max }$ and minimum pressure $\mathrm{p}_{\min }$.

Hurricane Andrew in 1992 cost the United States about 25 billion dollars (Wakimoto and Black, 1994; NOAA, 1992). The landfall of the hurricane has been well studied by MM5 simulations (Liu et al., 1997). This hurricane began as a tropical disturbance near the west coast of Africa on 14 August 1992. It developed and then weakened till 1200 UTC 21 August 1992 when the upper level low to its West-North-West started to split from the northern low and became a trough which continued to withdraw and led to the vertical shear decreasing around Hurricane Andrew. It reached hurricane strength $\left(\mathrm{U}_{\max }>33 \mathrm{~m} \mathrm{~s}^{-1}\right.$ at the surface) on 22 August. From 0000 UTC 21 August to 1800 UTC 23 August, its central pressure decreased from 1014 to $922 \mathrm{hPa}$, a $92 \mathrm{hPa}$ drop at a rate of $2.2 \mathrm{hPa} / \mathrm{h}$, which meets the criteria for a rapidly deepening hurricane as defined by Holliday and Thompson (1979). After reaching its maximum strength, Hurricane Andrew weakened temporarily, but it strengthened again as it crossed over Florida Strait till landfall. Then Hurricane Andrew weakened as it traversed Florida for the next four hours (from 0830 UTC to 1230 UTC on 24 August).

The MM5 was initialized by the NCEP/NCAR reanalysis, with enhancements by US Navy radiosondes, additional surface observations and sea surface temperature data (Kalnay et al., 1996; Liu et al., 1997), at 1200 UTC 21 August 1992 at which time Hurricane Andrew started to strengthen rapidly. The model was then integrated for 24 hours. The 24 sigma layers in the model are chosen to have high resolution in the planetary boundary layer and a moderate grid, with $18 \mathrm{~km}$ horizontal resolution and $124 \times 94$ grid points, is run nested within a coarse grid, with $54 \mathrm{~km}$ horizontal resolution and $82 \times 64$ grid points, centered on $75 \mathrm{~W}, 25 \mathrm{~N}$ and $72 \mathrm{~W}, 24 \mathrm{~N}$, respectively, and with time-steps of $120 \mathrm{~s}$ and $40 \mathrm{~s}$, respectively.

The boundary conditions of the outer domain are from a linear interpolation of the 12-h NCEP/NCAR reanalysis (Kalnay et al., 1996). The coarser grids provide the finer grids with time-dependent boundary conditions, and the solutions of the finer grids feed back to the coarser grids every time-step due to the two-way nesting.

Two simulations for Hurricane Andrew were conducted. One was with the standard MM5 diffusion scheme, and another was with the new scheme described in section 3.2. Figs. 6 and 7 show the time-series of the surface minimum pressure (central pressure) and surface maximum (sustained) wind velocity, respectively, for the 6hourly observations and simulations for the 24 hour period from 1200 UTC 21 August to 1200 UTC 22 August 1992.

The comparative simulation results show that the new scheme improves noticeably the model accuracy in predicting the intensity of the hurricane. It is seen from Figs. 6 and 7 that the improved outputs are closer to the observations than those from the original simulations. 


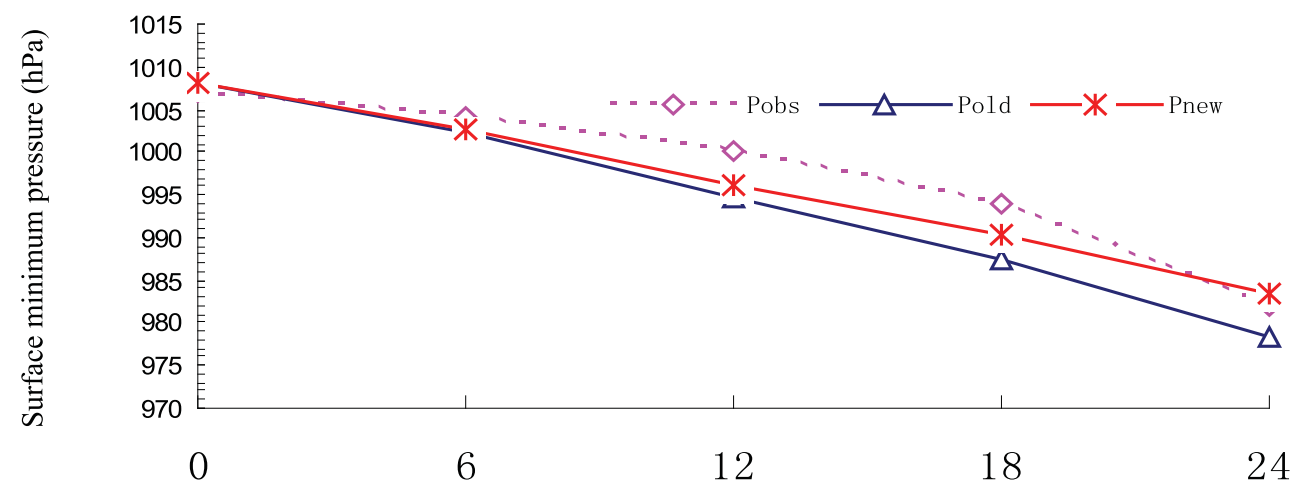

Fig. 6. Comparison of observed changes in the surface minimum pressure, $P_{o b s}$, of the Andrew (1992) with the time from 1200 UTC 21 August to 1200 UTC 22 August, 1992 with the simulated outputs of pressure by the old and new MM5 versions, $P_{\text {old }}$ and $P_{\text {new, }}$ respectively.

$P_{o b s}$ - observed pressure

$P_{\text {old }}$ - simulated pressure by the old MM5

$P_{\text {new }}$ - simulated pressure by the new MM5

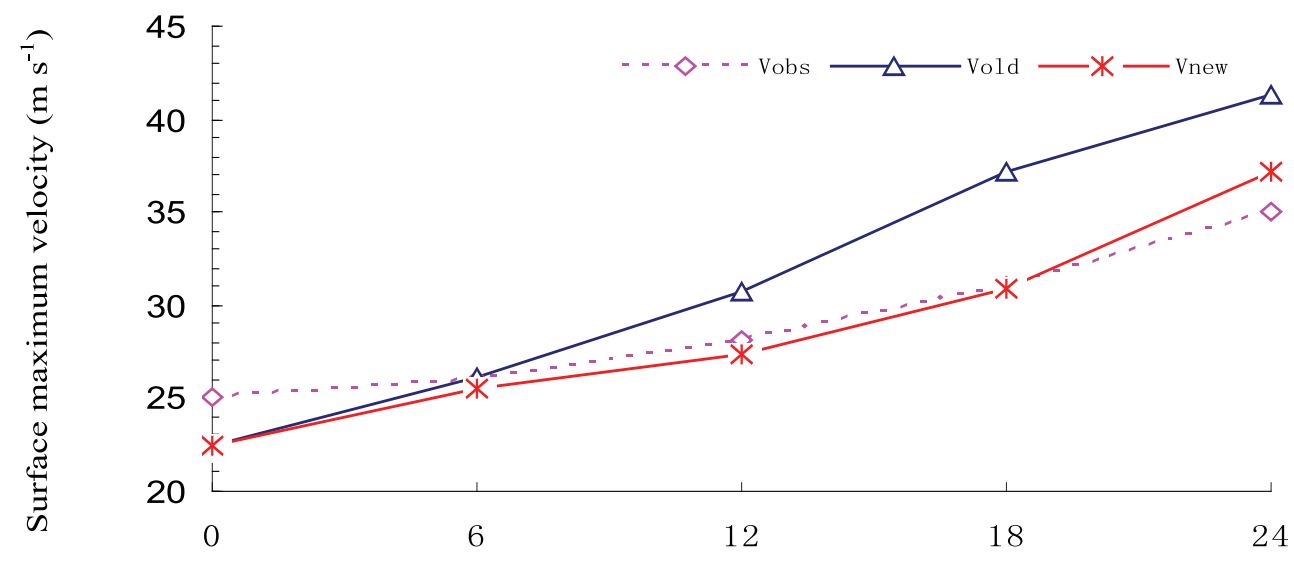

Fig. 7. Same as in Fig. 6 but for the surface maximum wind velocity.

$V_{o b s}$ - observed wind velocity

$V_{\text {old }}$ - simulated wind velocity by the old MM5

$V_{\text {new }}$ - simulated wind velocity by the new MM5

In fact, a yearlong continuous simulation that contains the sum of 36524 hour runs has been done using the same MM5 model with the same 24 hour simulative settings, from 0000 UTC 1 May 2005 till 0000 UTC 30 April 2006 to validate the reliability of improvement by this physics-based scheme. The one-year averaged (averaged over 36524 hour simulations) 
fractional percentage improvement rates (the fractional percentage improvement rate $I$ of the root-mean-square-error (RMSE) for a variable is defined as $I=100^{*}\left(E_{0}-E_{n}\right) / E_{o}(\%)$ with $E_{o}$ and $E_{n}$ as the errors by the original and new schemes, respectively) are $5.57 \%, 9.32 \%$ and $4.41 \%$ for the latitudinal $(\mathrm{u})$, longitudinal $(\mathrm{v})$ velocities and temperature, respectively.
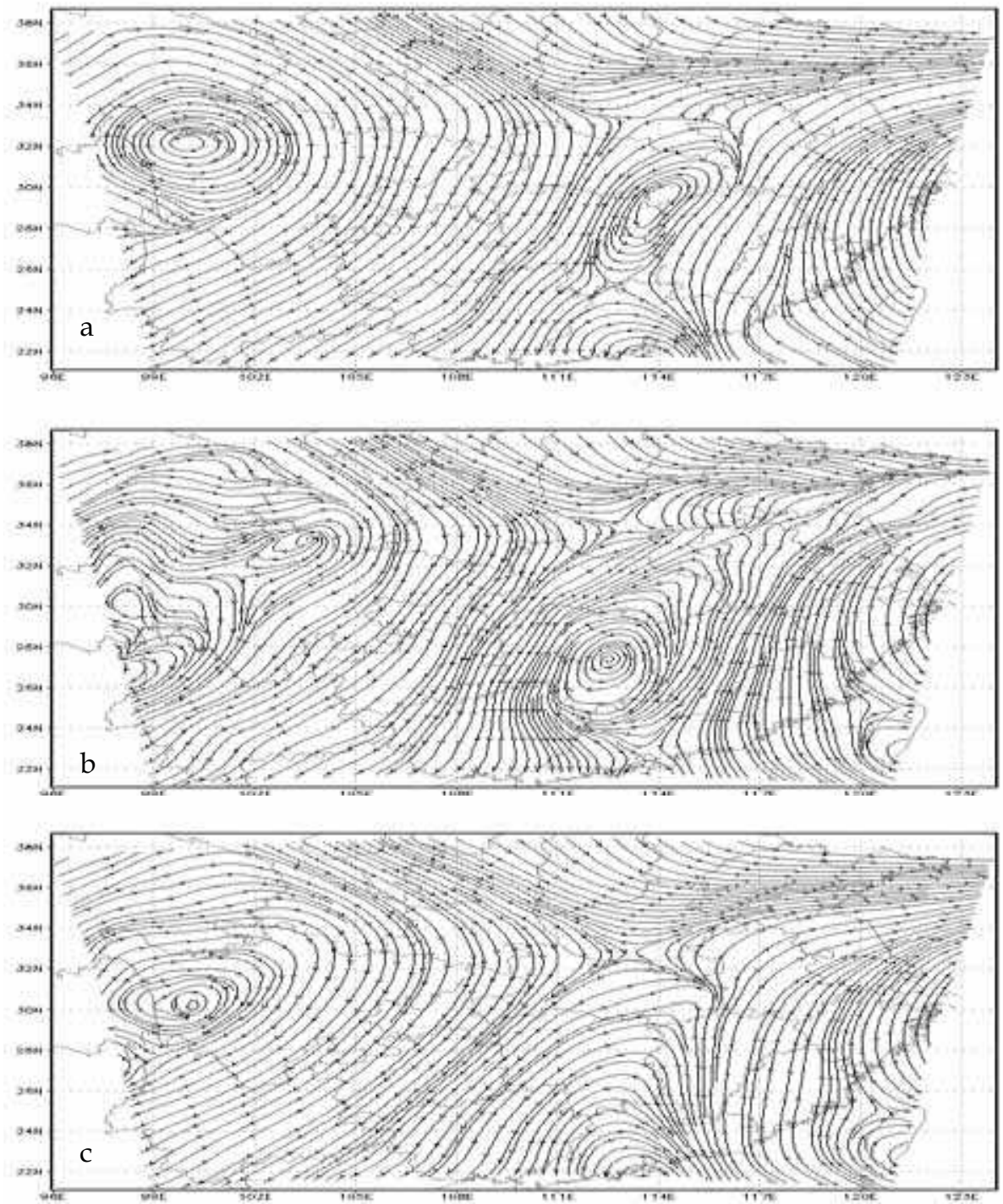

Fig. 8. Comparison of the $500 \mathrm{hPa}$ reanalysis data at 0000 UTC 3 September 2005 (a) with the 24 hour outputs of the horizontal wind field at 0000 UTC 3 September 2005 with the data at 0000 UTC 2 September 2005 as the initial conditions between the old horizontal diffusion scheme (b) and the new scheme (c) used. 
As shown in the case of the viscous Burgers equation where there is a Gibbs oscillation near the "shock wave" when the original diffusion scheme is employed, it is prominent that the outputs from the control runs are generally "noisier" than those from the runs using the physics-based scheme. Fig. 8 illustrates an example among the yearlong continuous simulations, which is for comparison of the reanalysis data at 0000 UTC 3 September 2005 with the 24 hour horizontal wind outputs at 0000 UTC 3 September 2005 with the data at 0000 UTC 2 September 2005 as the initial conditions. It is seen from Fig. 8 that, as a whole, the improvement in the longitudinal velocity $(\mathrm{v})$ is larger than that in the latitudinal one $(\mathrm{u})$, but we would like to particularly mention that the huge anticyclone in the western part of the domain is distinctly improved after the new scheme has been employed.

In summary, the present finite difference form of the fourth-order horizontal diffusion scheme employed in a meso-scale model is not consistent with the second law of thermodynamics and should be reformulated by a new approach based on the physical law. The potential of improving the simulative accuracy of a meso-scale numerical weather prediction model via this thermodynamics-based scheme is illustrated through the case of the one-dimensional viscous Burgers equation running to a steady flow as well as a series of simulations of weather events. The new scheme suggested in this chapter resulted in decrease root-mean-square errors and improved forecasts in all the simulations.

\section{Understanding tropical cyclone frequency variability in terms of thermodynamic principles}

\subsection{A brief introduction}

The observations show that the tropical cyclone (TC) numbers tend to become decreasing over some oceanic basins during the recent multiple decades in a warming environment. A methodology of understanding the mechanism responsible for such seemingly counterintuitive phenomena is suggested in this chapter.
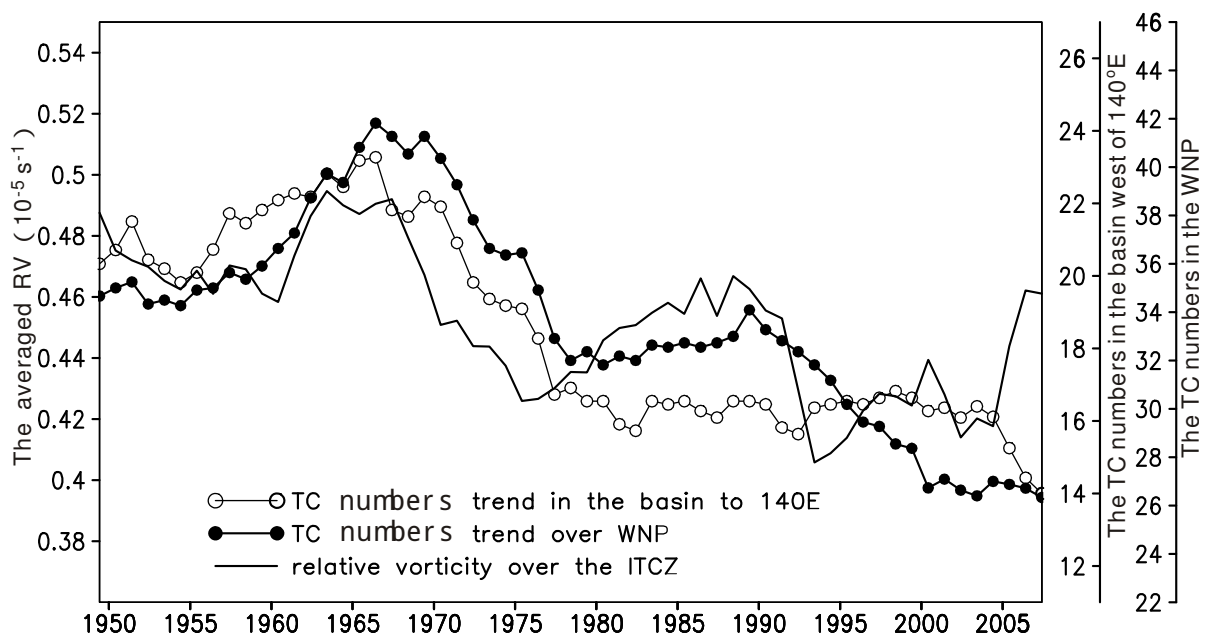

Fig. 9. The long term evolution series for the TC numbers in the WNP and in the basin west of 140 E E as well as the averaged RV (in $10^{-5} \mathrm{~s}^{-1}$ ) in the ITCZ of monsoon trough type during 1949-2007 (see the text for data source). 
Here, as mentioned above, the WNP over which the TC occurrence frequencies tended to decrease with minor fluctuations from late 1960s (Fig. 9) is taken as an example to discuss the possible mechanism responsible for the causation.

In Figure 9 the data for TC numbers are from the Tropical Cyclone Annals (CMA 1949-2007) and the relative vorticity (RV) is based on the National Centers for Environmental Prediction/National Center for Atmospheric Research (NCEP/NCAR) 2.5 $\times 2.5^{\circ}$ (latitudelongitude grid) reanalysis data.

In view of the fact that the majority of TCs are originated around the intertropical convergence zone (ITCZ) and that the intensity and position of ITCZ can be described reasonably in terms of the RV (see the text below for further details), this study is arranged as follows: the main source of TC genesis and ITCZ of monsoon trough type over the WNP are described in the next section; discussions on the ITCZ variabilities and their possible causes are given in section 4.3 with focus on SSTs changes and the effect of SSTs pattern on the ITCZ migration; the further discussions and conclusive remarks are presented in section 4.4.

\subsection{The main source of TC genesis and the ITCZ}

According to the previous studies (Gray 1967; Bates 1970; Charney 1971), 80-85\% of TCs are originated in the ITCZ or just on its poleward side, and the ITCZ of monsoon trough type located in the basin west of $140 \mathrm{oE}$ is the main origin of TCs over the WNP. On the other hand, the necessary conditions of TC genesis and development include higher SSTs, stronger low level vorticity, weaker vertical wind shear, and higher latitudinal position of subtropical anticyclone ridge/ITCZ, and, these conditions are however not equally important. Among them low level vorticity should be the fundamental factor for TC genesis since initial disturbances are the embryo of TCs. In addition, the intensity of the ITCZ as a main system generating TCs can be described in terms of the RV (e.g. use RV at $850 \mathrm{hPa}$ for defining the ITCZ, as is seen in Chan and Evans (2002)). Indeed the TC numbers over the WNP and the basin west of $140^{\circ} \mathrm{E}$ have a high correlation with the RV around the ITCZ, as is seen in Fig. 9 where these numbers show almost synchronous changes with those of the RV. The corresponding correlation coefficients for the WNP and the basin west of $140^{\circ} \mathrm{E}$ are 0.6552 and 0.6614 at the 0.001 significance level, respectively. It is noticed, in Ma and Chen (2009), that a 10-year running mean to the annual TC frequency data and NCEP typhoon season mean wind data has been applied to get the long term evolution series of the averaged TC numbers and RV(in $10^{-5} \mathrm{~s}^{-1}$, at $925 \mathrm{hPa}$ ) in the ITCZ of monsoon trough type for the period 1949-2007, and, that July-October (JASO hereafter) is defined as the typhoon season since JASO is the most frequent season of TCs over the WNP. It will therefore be a reasonable way to discuss the causality between the TC frequency trend and warming SSTs over the WNP via the ITCZ variability as the medium.

\subsection{The ITCZ variabilities and their possible causes}

\subsubsection{The ITCZ variation}

The analyses below are based on the NCEP/NCAR $2.5^{\circ} \times 2.5^{\circ}$ resolution reanalysis data for horizontal winds from which the ITCZ fields in terms of RV are figured out via the definition of RV at constant pressure

$$
\varsigma_{p}=\left(\frac{\partial v}{\partial x}\right)_{p}-\left(\frac{\partial u}{\partial y}\right)_{p}
$$


where $\varsigma_{p}, u$ and $v$ are the $\mathrm{RV}$, the latitudinal and longitudinal velocities at constant pressure, respectively, and the $2.0^{\circ} \times 2.0^{\circ}$ data for the SST fields (Kalnay et al. 1996). All the means are calculated against the period of JASO as mentioned above.
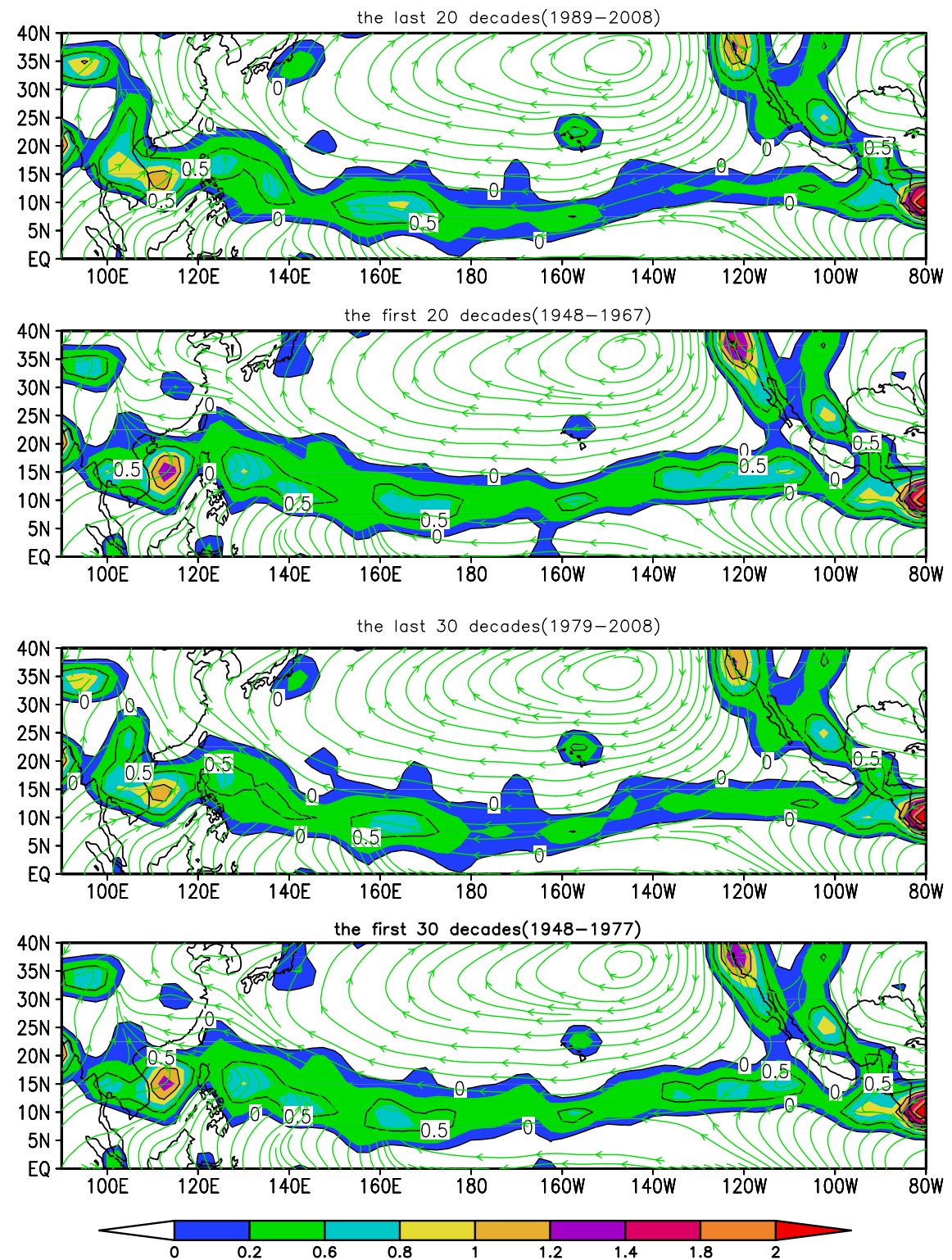

Fig. 10. Comparison of the stream fields superimposed by the positive RV at $925 \mathrm{hPa}$ (isolines are for the positive RV in $10^{-5} \mathrm{~s}^{-1}$ ) during JASO over the WNP between the first and last 20-year/30-year means (as marked above the respective panel). 
Figure 10 shows the stream fields superimposed by the positive RV at $925 \mathrm{hPa}$ during JASO over the WNP. It is found from near the equator in Fig. 10 that the zones of positive RV in the RV field can simply tell the general position of the convergence zones in the stream fields. This convergence zones should be able to represent the ITCZs due to the fact that the ITCZ is mainly formed by the trade winds converging (e.g., Bjerknes et al. 1969; Holton and Wallace 1971). In fact, as mentioned in section 4.2, the attempt using RV at $850 \mathrm{hPa}$ for defining the ITCZ has been done (e.g. Chan and Evans 2002). However, the RV in terms of $850 \mathrm{hPa}$ is not continuous in some sections of ITCZs over the Pacific owing to its weaker intensity (figures not shown here). Therefore the RV at $925 \mathrm{hPa}$ that is more continuous and smoother than that at $850 \mathrm{hPa}$ is chosen instead in this chapter.

It is noticed from Fig. 10 that the variabilities of the ITCZ of monsoon trough type associated with the reduction in the TC numbers over the WNP under warming SSTs during the last several decades are involved with the following two factors: (1) the intensity of the ITCZ of monsoon trough type as the main origin of TCs over the WNP, in terms of RV at $925 \mathrm{hPa}$, was weakened, and (2) the position of the ITCZ shifted into the latitudes further south (see also Fig. 11), both of which would contribute to the decrease in TC numbers over the WNP. Next we will specifically discuss these two aspects.

\subsubsection{The implication of SSTs variation}

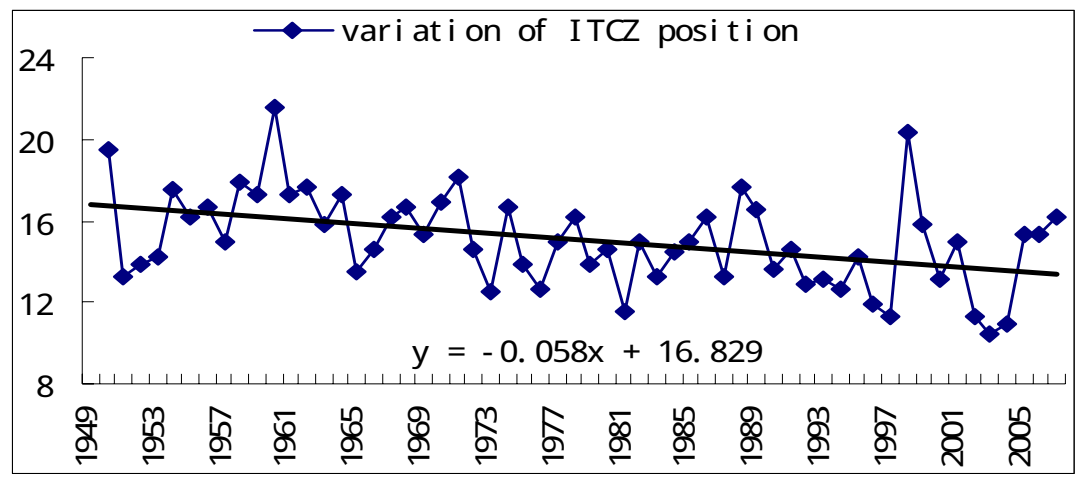

Fig. 11. The illustration of changes in the average position of the ITCZ from 1949 to 2007. Here, the central position of the ITCZ is determined via singling out the points with maximum positive $\mathrm{RV}$ along the longitudinal direction within the $100^{\circ} \mathrm{E}-140^{\circ} \mathrm{E}$ and then averaging their respective latitudinal position.

Figure 11 shows the every 20-year means of SSTs over the WNP for JASO during 1949-2008. It is seen from Fig. 11 that the SSTs over the North Pacific are gradually increased during the recent 60 years, especially, the areas circled with the isotherm of $28^{\circ} \mathrm{C}$ that is defined as the critical temperature for the warm pool (Ho et al. 1995) extended eastward prominently. This cross-equatorial area of warm pool was limited within the western Pacific initially which has extended straightforwardly till the eastern Pacific so as to be connected eventually from the western up to eastern Pacific as seen in the panel for the last 20-year period (1989-2008) of Fig. 10. Since there is a close relationship between SSTs and surface wind divergence and convection over the tropical oceans or the ITCZs (Graham and Barnett 1987; Lau et al. 1997; 
Lindzen and Nigam 1987) the following questions are then raised: how the SSTs or their gradient influence the intensity of the ITCZ, and why the sea surface warming extent reached around the western Pacific covering some part of the warm pool is not as dramatic as those over the central and eastern Pacific. The latter is relevant to the first factor of the ITCZ variabilities mentioned above. A potential clue would be implied by the modern nonlinear non-equilibrium thermodynamics.

For an isolated thermodynamic system, the state function of the system, entropy s per unit mass, will spontaneously increase with time according to the second law of thermodynamics, which can be expressed by the formula (Prigogine 1955; De Groot and Mazur 1962)

$$
\frac{d s}{d t} \geq 0
$$

and be usually called the spontaneous entropy increment principle. As a result, an isolated system will spontaneously tend to homogenization. However, for an open system with the diabatic heating rate $Q$ transferred through its boundaries, Equation (2) should be modified to

$$
\frac{d s}{d t} \geq \frac{Q}{T}
$$

where $T$ is the temperature (in $\circ \mathrm{K}$ ) of the system. The nature of the second law of thermodynamics shows that, if there exists difference initially, heat (particles) will be spontaneously transferred (diffused) from part with higher $\mathrm{T}$ (concentration) to that with lower $\mathrm{T}$ (concentration). Any many-body system like the atmosphere or ocean must be controlled by the second law of thermodynamics and, in fact, the entropy flow properties of the atmospheric systems have been revealed based on this law (Liu and Liu 2005; Liu et al. 2006; Liu and Liu 2007; Xu and Liu 2008).

Specifically, if there exists difference of temperature spatially (say, on sea surface), the original part of warmer sea surface will diffuse its thermal energy (the inner energy, proportional positively to temperature via the formula of $e=C_{p} T$ where $e$ is the inner energy per unit mass, $C_{p}$ is the specific heat at constant pressure and $T$ is temperature) to its surrounding parts with lower temperature. As a consequence, compared with the surrounding areas the original warmer area (e.g., the area related with the warm pool) will experience a weaker warming under global warming since it will lose a certain amount of heat via the diffusive process at the same time, and vice versa (Fig. 12 showing the case for the North Pacific is only an example in which it is demonstrated that the SSTs around the ITCZ of monsoon trough type have a smaller increment of temperature while those over the adjacent ITCZ sections near the central and eastern equatorial Pacific have larger increments). In view of that the ITCZ is caused, at least in the initial stages, mainly by the thermodynamic forcings such as the gradient in SST that has been regarded as playing more of a role than the absolute SST value with regard to convection and precipitation (Lindzen and Nigam, 1987) the ITCZ of monsoon trough type should indeed become weaker in response to more uniform SSTs or weakened SST gradient over there.

\subsubsection{The effect of SSTs pattern on the ITCZ migration}

As described above, in the warming environment the higher SSTs area circled with the isotherm of $28^{\circ} \mathrm{C}$ related to the warm pool has gradually extended eastward and been 
connected from the western to eastern Pacific eventually during the last 20 years (Fig. 12) so as to form an apparent zone of higher SSTs with a distinct gradient of nearly north-south direction created on the both northern and southern sides of this zone. Such a SST pattern will cause corresponding changes in the average temperature $T_{m}$ of an immediate air layer above the sea surface. Thus, in some regions to the north of the zone of higher temperature where the semi-geostrophic relation for the Tropics is valid (Lin and Chao 1998) a western wind component at the higher levels (e.g. at $925 \mathrm{hPa}$ ) should be superposed, which will cause a positive increment of the latitudinal velocity $u$ with $\Delta u>0$ (at the higher level), very similar to the thermal wind relation (Holton 1992; see Eq. (20) below):

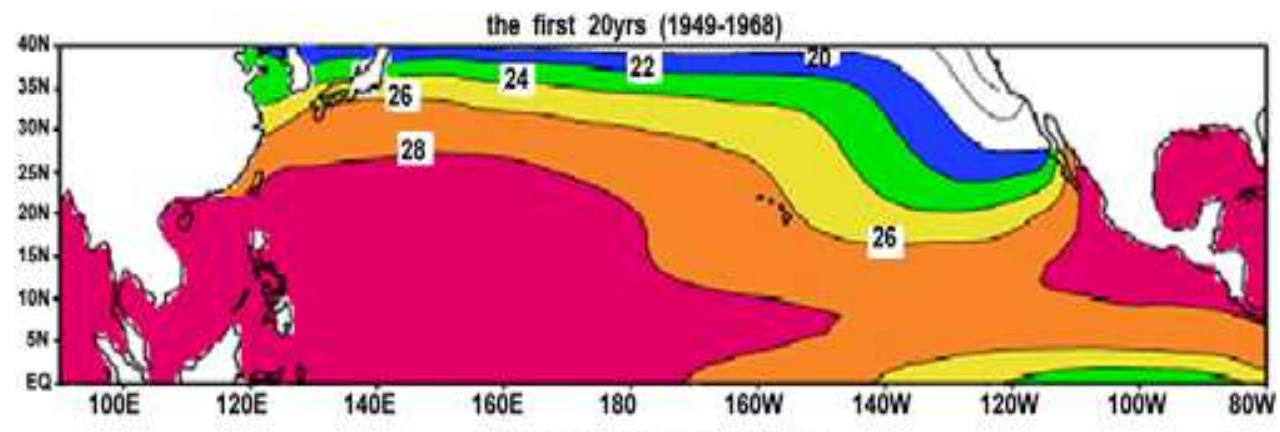

the second $20 y r 5$ (1960.1988)

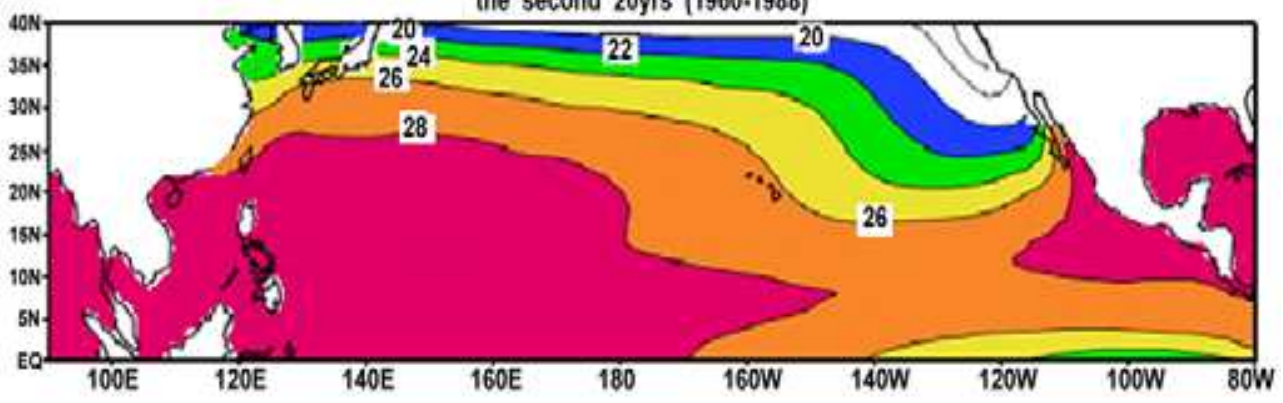

the third 20yrs (1989-2008)

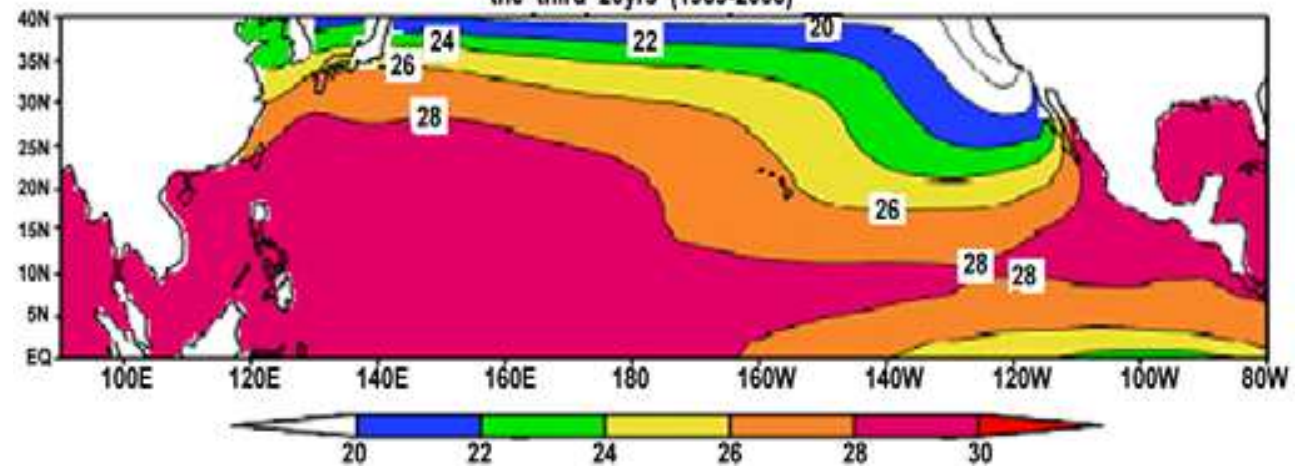

Fig. 12. The every 20-year-averaged SST fields (as marked above the respective panel; unit: $\left.{ }^{\circ} \mathrm{C}\right)$ for the North Pacific south of 40N during the period from 1949 to 2008. 


$$
\overrightarrow{\mathrm{V}}_{\mathrm{T}}=-\frac{R}{f} \ln \frac{p_{1}}{p_{2}} \nabla_{p} T_{m} \times \vec{k}
$$

where $\overrightarrow{\mathrm{V}}_{\mathrm{T}}$ denotes the thermal wind between the constant pressure layers $p_{1}$ (e.g. $1000 \mathrm{hPa}$ that is near the sea surface) and $p_{2}$ (e.g. $925 \mathrm{hPa}$ that is used for defining the ITCZ in terms of $\mathrm{RV}$ in this chapter); $\nabla_{p} T_{m}$ is the average temperature gradient with $T_{m}$ is the average temperature between $p_{1}$ and $p_{2} ; \vec{k}$ the unit vector in the vertical direction; and $R$ and $f$ are the gas constant for dry air and Coriolis parameter, respectively. In contrast, the latitudinal velocity $u$ to the south of the zone should be superposed by an eastern component as the gradient in SSTs in the south regions is reverse to that in the north ones. As a result, the RV, as is expressed by $\varsigma_{p}=\left(\frac{\partial v}{\partial x}\right)_{p}-\left(\frac{\partial u}{\partial y}\right)_{p}$, in the regions to the north of the zone of higher temperature will be decreased (at the higher level) since the term of $-\left(\frac{\partial u}{\partial y}\right)$ becomes smaller with the term of $\left(\frac{\partial v}{\partial x}\right)_{p}$ having a minor change in this case. At the same time, the RV in the regions to the south of the zone of higher temperature will be increased owing to the reversed gradient in SSTs or $T_{m}$ there.

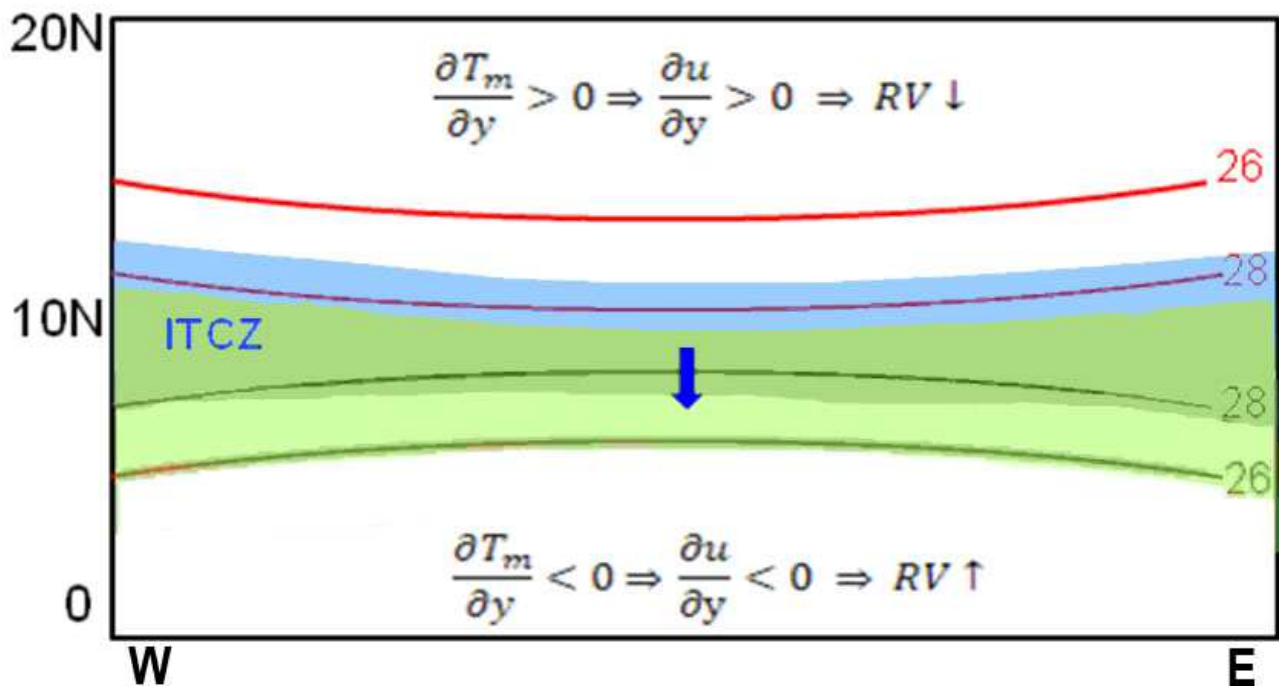

Fig. 13. The diagrammatic sketch for the proposed mechanism for a southern shift of the ITCZ coupled with RV which is contributive to the reduction in TC counts around the WNP (see the text for further details). The red lines represent SSTs showing sketchily the opposite temperate gradients (and the potentially-forced average temperature gradients $\frac{\partial T_{m}}{\partial y}$ within the immediate layer above the sea surface) in the both sides of the maximum SSTs. 
Taking the definition of ITCZ in terms of positive RV into account, we might expect that the part of the ITCZ to the north of the zone of high temperature will tend to weaken and even disappear as the result of reduction in RV there and, on the contrary, the part of the initial ITCZ to the south will enhance and even extend south further (see Fig. 13 for reference). That is able to be used to explain why the ITCZ migrates south apparently, as is relevant to the second factor of the ITCZ variabilities above.

As well-known to all, the necessary conditions for TC genesis are not equally important and, among them dynamical factors such as low level vorticity and vertical wind shear play a more important role than thermodynamic factors such as SST and moist instability as suggested on some simulative results (Sugi et al. 2002; McDonald et al. 2005; Chauvin et al. 2006). This study shows that, warmer SSTs in the WNP even caused fewer TCs, that is, warmer SSTs as one of the necessary conditions do not definitely lead to an increase in TC numbers, which might be attributed to the heterogeneous effects of complicated pattern of SSTs on RV as implied by the second law of thermodynamics with the thermal wind principle taken into account. This study further proves that low level RV associated with ITCZ variations should be a fundamental factor for TC genesis. Based on the analyses in this chapter, a new way of understanding the mechanism responsible for the causality among SSTs, RV and TC occurrence frequency over the WNP is then suggested. As a matter of fact, the WNP is only used as an example in this study and, the principle of the methodology illustrated herein is universal. This analysis can be also applied to the other oceanic basins worldwide than the WNP.

\section{Conclusive remarks}

In this chapter some crucial concepts and theories in modern thermodynamics have been applied to hurricane researches, which cover the potential mechanism responsible for the hurricane evolution investigated based on the entropy analyses, the simulative improvement of hurricane track forecast using the irreversible thermodynamic operator technique, as well as understanding the TC frequency variability according to the $2^{\text {nd }}$ law of thermodynamics. Indeed, since the atmosphere is a many-body system thermodynamics and statistical mechanics should be a very important approach to revealing the activities of the atmospheric vortices like hurricane. The results shown here are however very preliminary and, a larger sample of hurricanes and its statistical analyses are needed for further application to the operational forecasts in future.

Here we would like to stress that, back to the track and intensity forecasts of Hurricane Katrina with a complex life cycle (McTaggart-Cowan et al., 2007), it is found that some knotty forecast situations during Katrina might have been handled in a proper way using a forecast guidance scheme developed based on the relevant results in this chapter. For example, with regard to the forecast track errors, Knabb et al. (2005) particularly mentioned, in its section "d. Forecast and Warning Critique", the difficult forecast scenario associated with Katrina's westsouthwestward motion across the southern Florida peninsula and eastern Gulf of Mexico. We notice that all the entropy flow patterns in the vertical cross sections at 6-hourly intervals for Katrina from 00:00 UTC 26 to 00:00 UTC 27 August (figures not presented in this chapter) during which it moves across the southern Florida peninsula and eastern Gulf of Mexico indicate a distinct southerliness in Katrina's track orientation in addition to westering, showing a general agreement with its real west-southwestward motion (see Fig. 2). As for the average official intensity forecast errors during Katrina that are considerably larger than the 
corresponding Atlantic 10-year (1995-2004) averages and can be partly attributed, as stated in Knabb et al. (2005), to the fact that "Katrina was an unusually intense hurricane and underwent two rapid intensification periods, including the very rapid strengthening from Category 3 to 5 on the morning of 28 August" (Knabb et al. (2005), we would like to recall the proposition of "negative entropy flow is something very positive for a system to keep far from its equilibrium" and Fig. 3 in this chapter which shows that the increasing continuously strong negative entropy flow entering into Katrina till 00:00 UTC 28 August just precedes the period of very rapid intensification on that morning. In other words, the negative entropy flow analyses in the present chapter suggest that Katrina would meet with a rapid strengthening process immediately after 00:00 UTC 28 August. In view of that "accurately forecasting the timing and magnitude of such events remains an operational challenge, in part because the available intensity guidance models generally have little or no skill in forecasting rapid intensity changes" (Knabb et al., 2005), it is anticipated that a new-generation guidance model might benefit from the scheme based on the entropy flow analysis described in this chapter.

\section{Acknowledgments}

This work has been jointly supported by 973 Program (2009CB421500), the National Natural Science Foundation of China under Grants 41075048, 40633016, 40875029 and 40975036, as well as the Basic Research Project of the State Key Laboratory of Severe Weather, Chinese Academy of Meteorological Sciences (2008LaSWZI01).

\section{References}

Anthes, R.A., Hsie, E.-Y. \& Kuo, Y.-H.(1987). Description of the Penn State /NCAR Mesoscale Model Version 4 (MM4). NCAR Tech. Note, NCAR/TN-282+STR, National Center for Atmospheric Research, Boulder, CO.

Barsugli, J. J. \& Battist, D. S. (1998). The Basic Effects of Atmosphere-Ocean Thermal Coupling on Midlatitude Variability. J. Atmos. Sci. 55: 477-493.

Bates, J. R., (1970). Dynamics of disturbances on the Intertropical Convergence Zone. Quart. J. Roy. Meteor. Soc., 96: 677-701.

Becker, E. (2001). Symmetric Stress Tensor Formulation of Horizontal Momentum Diffusion in Global Models of Atmospheric Circulation. Journal of the Atmospheric Sciences 58: 269-282.

Bohren, C. F. \& Albrecht B. A. (1999). Atmospheric Thermodynamics, Oxford University Press, London.

Bronshtein, I. N. \& Semendyayev K. A. (1997). Handbook of mathematics, 3rd edition, SpringerVerlag, London,.

Burkhardt, U. \& Bercker E. (2005). A Consistent Diffusion-Dissipation Parameterization in the ECHAM Climate Model. Mon. Wea. Rev. 134: 1194-1204.

Cerveny, R. S., Lawrimore, J. Edwards, R. \& Landsea, C. (2007). Extreme Weather Records, Bull. Amer. Meteorol. Soc. 88: 853-860.

Chan, S.C. \& Evans, J. L. (2002). Comparison of the Structure of the ITCZ in the West Pacific during the Boreal Summers of 1989-93 Using AMIP Simulations and ECMWF Reanalysis.J.Climate.15: 3459-38.

Charney, J. G. (1971). Tropical cyclonegenesis and the formation of the Intertropical Convergence Zone, in W. H. Reid, (ed.) Mathematical Problems of Geophysical Fluid Dynamics, Lectures in Applied Mathematics, Vol.13,. Amer. Math. Soc., 383 pp. 
Chauvin, F., Royer J. -F. \& Déqué, M. (2006). Response of hurricane-type vortices to global warming as simulated by ARPEGE-climate at high resolution, Clim. Dyn. 27: 377 399.

Cheng, S. I. (1975). A Critical review of numerical solution of Navier-Stokes equations. Progress in Numerical Fluid Dynamics, Lecture Note in Physics, 41: 97-99.

CMA (1949-2007). Tropical Cyclone Annals, China Meteorological Press, 150 pp (each).

Crandall, M.G. \& Majda, A. (1980). Monotone difference approximations for scalar conservation laws. Mathermatics of Compatations, 34: 1-21.

Curry, J. A. (1999). Thermodynamics of Atmospheres and Oceans, Academic Press, San Diego.

De Groot, S. R. \& Mazur, P. (1962). Non-equilibrium thermodynamics, North-Holland Publishing Company.

Duane, G. S. \& Curry, J. A. (1997). Entropy of a connecting water-air system and the interpretation of cloud morphogenesis. Q. J. R. Meteorol. Soc. 123: 605- 629.

Dudhia, J. (1993). A nonhydrostatic version of the Penn State-NCAR mesoscale model: Validation tests and simulation of an Atlantic cyclone and cold front. Mon. Wea. Rew. 121: 1493-1513.

Easterling, D. R., Evana, J. L., Grosman , P. Y. Karl, T. R.,. Kunkel, K. E \& Ambenje, P. (2000). Observed Variability and Trends in Extreme Climate Events: A Brief Review, Bull. Am. Metor. Soc., 81: 417-425.

Egger, J. (1999). Numerical Generation of Entropies Mon. Wea. Rev. 127: 2211-2216.

Eliasen, E. \& Laursen, L. (1990). The effects of horizontal resolution and diffusion in a twolayer general circulation model with a zonally symmetric forcing. Tellus 42A: 520530.

Elsner, J. B. \& Jagger, T. H. (2009). Hurricanes and Climate Change, Springer.

Fraedrich, K. \& Blender, R. (2003). Scaling of atmosphere and ocean temperature correlations in observations and climate models, Phys. Rev. Lett. 90 (10) (108501 14). DOI: 10.1103/PhysRevLett.90.108501.

Gade, H. G. \& Gustafson, K. (2004). Application of classical thermodynamics principle to study of oceanic overturning circulation, Tellus 56A(4): 371-387.

Glansdorff, P. \& Prigogine, I. (1971). Thermodynamic theory of structure, stability and fluctuations, Wiley-Interscience, London,.

Graham, N. E. \& Barnett, T. P. (1987). Sea surface temperature, surface wind divergence and convection over tropical oceans, Science 238: 657-659.

Gray, W. M. (1967). Global view of the origin of tropical disturbances and storms, Mon. Wea. Rev., 96: 669-700.

Grell, G.A., Dudhia, J. \& Stauffer, D.R. (1995). A description of the fifth generation Penn State/NCAR mesoscale model (MM5). NCAR Tech. Note, NCAR/TN-398+STR, National Center for Atmospheric Research, Boulder, CO.

Haken, H. (1983). Advanced Synergetics, Springer-Verlag.

Haltiner, G. J. \& Martin, F. L. (1957). Dynamical and Physical Meteorology, McGraw-Hill, New York,

Ho, C. -R., Yan, X. -H. \& Zheng, Q. (1995). Satellite observations of upper-layer variabilities in the western Pacific warm pool, Bull. Amer. Meteor. Soc. 76: 669-679

Holliday, C.R. \& Thompson, A.J. (1979). Climatological characteristics of rapidly intensifying typhoons. Mon. Wea. Rev. 107: 1022-1034.

Holton, J. R.(1992). An Introduction to Dynamic Meteorology, Academic Press.

Kalnay, E. et al (1996). The NCEP/NCAR 40-year reanalysis project, Bull. Amer. Meteor. Soc., 77: 437-471. 
Karl, T. R., Kukla, G., Razuvayev, V. N., Changery, M. J., Quayle, R. G., Heim R. T., Jr., Easterling, D. R. \& Fu C. B. (1991). Global warming: evidence for asymmetric diurnal temperature change, Geophys. Res. Lett. 18: 2253-2256.

Katchalsky A. \& Curran, P. F. (1965). Non-equilibrium Thermodynamics in Biophysics (Harvard University Press, Cambridge, Mass,

Knabb, R. D., Rhome, J. R \& Brown, D. P. (2005). Tropical Cyclone Report: Hurricane Katrina (23-30 August 2005) (available online at http://www.nhc.noaa.gov/pdf/TCRAL122005_Katrina.pdf).

Lau, K. -M., Wu, H. -T. \& Bony, S. (1997). The role of large-scale atmospheric circulation in the relationship between tropical convection and sea surface temperature, $J$. Climate, 10: 381-392.

Laursen, L. \& Eliasen, E. (1989). On the effects of the damping mechanisms in an atmospheric general circulation model. Tellus A 41: 385-400.

Lin, Y. \& Chao, J. P. (1998). The processes of tropical semi-geostrophic adaptation, Science in China (Series D, 41: 566-573.

Lindzen, R. S. \& Nigam, S. (1987). On the role of sea surface temperature gradients in forcing low level winds and convergence in the tropics, J. Atmos. Sci. 44: $2440-2458$.

Liu, C. \& Liu, Y. (2004). Negative entropy flow and its effect on the organization of synopticscale severe atmospheric systems. Geophys. Res. Lett. 31, L01108, doi: 10.1029/2003G018071.

Liu, C. \& Liu, Y. (2005). An attempt at improving a global spectral model by incorporating the second law of thermodynamics. Geophys. Res. Lett. 32, L03806, doi:10.1029/2004GL021602.

Liu, C. Liu, Y., \& Luo, Z. (2009). Improving numerical simulation of a hurricane by irreversible thermodynamic operators, Atmos. Res., 93: 44-49, doi:10.1016/j.atmosres.2008.10.012.

Liu, C., Liu, Y. \& Xu, H. (2006). A physics-based diffusion scheme for numerical models, Geophys. Res. Lett. 33, L12805, doi:10.1029/2006GL025781.

Liu, C., Liu, Y. \& Xu, H. (2009). A New Diffusion Scheme for Numerical Models Based on Full Irreversibility, Weather and Forecasting, 24: 595-600, DOI: 10.1175/2008WAF2222145.1.

Liu, C., Xu, H. \& Liu, Y. (2007). Linking entropy flow with typhoon evolution: a case-study, Journal of Physics D: Applied Physics, 40: 6694-6704.

Liu, C. et al. (2010). Implication of entropy flow for the development of a system suggested by the life cycle of a hurricane, Modern Physics Letters B (MPLB) 24 :1747-1757.

Liu, Y. \& Liu, C. (2007). On the entropy flow properties of a severe tropical storm, Appl. Phys. Lett. 91, 014103. DOI: 10.1063/1.2753538.

Liu, Y. \& Liu, C. (2008). Entropy flow and the evolution of a storm, Entropy, 10: 430-440, DOI:10.3390/e10040430. 1004-4965(2008)03-0038-07.

Liu, Y. \& Liu, C. (2009). Negative entropy flow and the life-cycle of a severe tropical storm, Atmos. Res., 9: 39-43, doi:10.1016/ j.atmosres. 2008. 10.013.

Liu, Y., Zhang, D.-L, \& Yau, M. K. (1997). A multiscale numerical study of Hurricane Andrew (1992), Part I: Explicit simulation and verification. Mon. Wea. Rew. 125: 3073-3093.

Ma, L. \& Chen, L. (2009). The relationship between global warming and the variation in tropical cyclone frequency over the western North Pacific, J. Trop. Meteor., 15: 38-44.

Manton, M. \& Eral, J. (2001). Trends in extreme daily rainfall and temperature in Southeast Asia and the South Pacific: 1961-1998, Int. J Climatol. 21: 269-284.

Mason, B. J. (1971). Physics of Clouds (Oxford University Press, London,. 
McBride, J. L. \& Ramsay, H. (2009). Relationship between tropical cyclone activity and sea surface temperature in the southern hemisphere, 2ed International Summit on Hurricanes and Climate Change, May 31 - June 5, 2009, Corfu, Greece,p 23.

McDonald, R.E., Bleaken, D.G., Creswell, D. R., Pope, V. D. \& Senior, C.A. (2005). Tropical storms: representation and diagnosis in climate models and the impact of climate change. Clim. Dyn. 25: 19-36.

McTaggart-Cowan, R., Bosart, L. F., Gyakum, J. R.\& Atallah, E. H. (2007). Mon. Wea. Rev. 135: 3905-3926.

Nitschke, K., Bestehorn, M. \& Thess, A. (1998). Square cells in surface-tension-driven Bénard convection. J. Fluid Mech. 356: 155 - 197.

Nicolis, C. (2002). Irreversible thermodynamics of a simple atmospheric Model.. Int. J. Bifurcation and Chaos 12: 2557-2566.

NOAA (1992). Storm Data. Department of Commerce Rep.34 (8).

Olby, R. (1971). Schrodinger's problem: What is life?. J. Hist. Biol. 4:119-148.

Onsager, L. (1931). Reciprocal relations in irreversible processes. I., Phys. Rev. 37: 405-426.

Ozawa, H. \& Ohmura, A. J. (1997). Thermodynamics of a global-mean state of the atmosphere - a state of maximum entropy increase. J. Climate 10(3): 441-445.

Pielke, R. A. (1984). Mesoscale meteorological modeling. Academic Press, Orlando.

Perkey, D. J. \& Kreitzberg, W. (1976). A time-dependent lateral boundary scheme for limited area primitive equation models. Mon. Wea. Rev. 104: 744-755.

Prigogine I. (1955). Introduction to thermodynamics of irreversible Processes, Charles C. Thomas Publisher.

Ruelle, D. P. (2003). Extending the definition of entropy to nonequilibrium steady states. Proc. Natl. Acad. Sci. USA 100: 3054-3058.

Schrödinger, E. (1944). What Is Life? Cambridge University Press.

Smagorinsky, J. (1963). General circulation experiments with the primitive equations: I. The basic experiment. Mon. Wea. Rew. 91: 99-164.

Stephenson, D. B. (1994). The Impact of Changing the Horizontal Diffusion Scheme on the Northern Winter Climatology of a General Circulation Model. Q. J. R. Meteorol. Soc. 120: 211-226.

Sugi, M., Noda, A. \& Sato, N. (2002). Influence of global warming on tropical cyclone climatology: an experiment with the JMA global model, J. Meteorol. Soc. Japan, 80: 249-272.

Tsonis, A. A. (2002). An introduction to atmospheric thermodynamics, Cambridge University Press, Cambridge, UK,.

Wakimoto, R.M. \& Black, P. G. (1994). Damage survey of Hurricane Andrew and its relationship to the eyewall. Bull. Amer. Meteor. Soc. 75: 189-200.

Wang, C., Li, David S. \& Enfield, B. (2008). Atlantic warm pool acting as a link between Atlantic multidecadal oscillation and Atlantic tropical cyclone activity, Geochem. Geophys. Geosys. 9: 1-17.

Wang, S. W. \& Gong, D.Y. (2000). Enhancement of the Warming Trend in China. Geophsys.Res. Lett. 27: 2581-2584.

von Storch, H. (2008). An Attempt to Homogeneously Describe 60 Years Statistics of TC Activity in East Asia, 1948-2007, 2008 Taiwan Climate Workshop, 18 November 2008, Taipei, Taiwan, China.

Xu, H. \& Liu, C. (2008). Entropy flow properties of a typhoon as simulated by a meso-scale model, Europhys. Lett., 83, 18001.doi: 10.1209/0295-5075/83/18001.

Zdunkowski, W. \& Bott, A. (2004). Thermodynamics of the Atmosphere, Cambridge University Press, Cambridge, UK. 


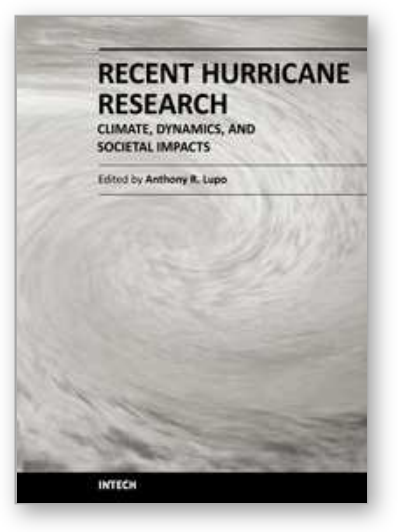

\author{
Recent Hurricane Research - Climate, Dynamics, and Societal \\ Impacts \\ Edited by Prof. Anthony Lupo
}

ISBN 978-953-307-238-8

Hard cover, 616 pages

Publisher InTech

Published online 19, April, 2011

Published in print edition April, 2011

This book represents recent research on tropical cyclones and their impact, and a wide range of topics are covered. An updated global climatology is presented, including the global occurrence of tropical cyclones and the terrestrial factors that may contribute to the variability and long-term trends in their occurrence. Research also examines long term trends in tropical cyclone occurrences and intensity as related to solar activity, while other research discusses the impact climate change may have on these storms. The dynamics and structure of tropical cyclones are studied, with traditional diagnostics employed to examine these as well as more modern approaches in examining their thermodynamics. The book aptly demonstrates how new research into short-range forecasting of tropical cyclone tracks and intensities using satellite information has led to significant improvements. In looking at societal and ecological risks, and damage assessment, authors investigate the use of technology for anticipating, and later evaluating, the amount of damage that is done to human society, watersheds, and forests by land-falling storms. The economic and ecological vulnerability of coastal regions are also studied and are supported by case studies which examine the potential hazards related to the evacuation of populated areas, including medical facilities. These studies provide decision makers with a potential basis for developing improved evacuation techniques.

\title{
How to reference
}

In order to correctly reference this scholarly work, feel free to copy and paste the following:

Chongjian Liu, Ying Liu, Zhexian Luo, Xiaotu Lei, Donghai Wang and Xiaogang Zhou (2011). Studies of the Hurricane Evolution Based on Modern Thermodynamics, Recent Hurricane Research - Climate, Dynamics, and Societal Impacts, Prof. Anthony Lupo (Ed.), ISBN: 978-953-307-238-8, InTech, Available from: http://www.intechopen.com/books/recent-hurricane-research-climate-dynamics-and-societal-impacts/studiesof-the-hurricane-evolution-based-on-modern-thermodynamics

\section{INTECH}

open science | open minds

\author{
InTech Europe \\ University Campus STeP Ri \\ Slavka Krautzeka 83/A \\ 51000 Rijeka, Croatia \\ Phone: +385 (51) 770447 \\ Fax: +385 (51) 686166
}

\author{
InTech China \\ Unit 405, Office Block, Hotel Equatorial Shanghai \\ No.65, Yan An Road (West), Shanghai, 200040, China \\ 中国上海市延安西路65号上海国际贵都大饭店办公楼405单元 \\ Phone: +86-21-62489820 \\ Fax: $+86-21-62489821$
}


www.intechopen.com 
(C) 2011 The Author(s). Licensee IntechOpen. This chapter is distributed under the terms of the Creative Commons Attribution-NonCommercialShareAlike-3.0 License, which permits use, distribution and reproduction for non-commercial purposes, provided the original is properly cited and derivative works building on this content are distributed under the same license. 